\title{
Mutant p53 regulates ovarian cancer transformed phenotypes through autocrine matrix deposition
}

\author{
Marcin P. Iwanicki, ${ }^{1}$ Hsing-Yu Chen, ${ }^{1}$ Claudia lavarone, ${ }^{1}$ Ioannis K. Zervantonakis, ${ }^{1}$ Taru Muranen, ${ }^{1}$ \\ Marián Novak,, ${ }^{2}$ Tan A. Ince, ${ }^{3}$ Ronny Drapkin, ${ }^{2,4}$ and Joan S. Brugge ${ }^{1}$ \\ 'Department of Cell Biology, Harvard Medical School, Boston, Massachusetts, USA. Dana-Farber Cancer Institute, \\ Department of Medical Oncology, Center for Molecular Oncologic Pathology, Boston, Massachusetts, USA. ${ }^{3}$ Stem Cell \\ Institute, University of Miami Miller School of Medicine, Miami, Florida, USA. ${ }^{4}$ Penn Ovarian Cancer Research Center, \\ Basser Center for BRCA, Perelman School of Medicine, University of Pennsylvania, Philadelphia, Pennsylvania, USA.
}

\begin{abstract}
High-grade serous ovarian carcinoma (HCS-OvCa) harbors p53 mutations and can originate from the epithelial cell compartment of the fallopian tube fimbriae. From this site, neoplastic cells detach, survive in the peritoneal cavity, and form cellular clusters that intercalate into the mesothelium to form ovarian and peritoneal masses. To examine the contribution of mutant p53 to phenotypic alterations associated with HCS-OvCA, we developed live-cell microscopy assays that recapitulate these early events in cultured fallopian tube nonciliated epithelial (FNE) cells. Expression of stabilizing mutant variants of $\mathrm{p} 53$, but not depletion of endogenous wild-type $\mathrm{p} 53$, in FNE cells promoted survival and cell-cell aggregation under conditions of cell detachment, leading to the formation of cell clusters with mesothelium-intercalation capacity. Mutant $\mathrm{p} 53^{\mathrm{R} 175 \mathrm{H}}$-induced phenotypes were dependent on fibronectin production, $\alpha 5 \beta 1$ fibronectin receptor engagement, and TWIST1 expression. These results indicate that FNE cells expressing stabilizing p53 mutants acquire anchorage independence and subsequent mesothelial intercalation capacity through a mechanism involving mesenchymal transition and matrix production. These findings provide important new insights into activities of mutant p53 in the cells of origin of HCS-OvCa.
\end{abstract}

Conflict of interest: The authors have declared that no conflict of interest exists.

Submitted: February 1, 2016 Accepted: May 24, 2016 Published: July 7, 2016

Reference information: JCI Insight. 2016;1(10):e86829. doi:10.1172/ji.insight.86829.

\section{Introduction}

High-grade serous ovarian carcinoma (HGS-OvCa) disseminates within the peritoneum, causing organ disruption that contributes to the poor clinical outcome associated with this disease (1-4). Initiation of HGS-OvCa can occur in the epithelium of the fimbriated end of the fallopian tube (5). Mutation of TP53 in the fimbriae epithelium is considered to be an initiating event in HGS-OvCa pathogenesis (6-8), as nearly $100 \%$ of serous ovarian tumors harbor these alterations (9-13).

HGS-OvCa dissemination involves the acquisition of the phenotypes that allow carcinoma cells to: (a) exfoliate from fimbriae into the peritoneal cavity, (b) cope with the proapoptotic stress induced by detachment from the basement membrane (anoikis) during transit through the fluids of the peritoneal cavity (14-16), and (c) attach to and clear the superficial layer of the mesothelium that encloses the organs in the peritoneal cavity (17-22). Although TP53 mutations are a hallmark of HGS-OvCa $(9,11,23)$, the role that mutant p53 variants play in the acquisition of these phenotypes is currently not known.

Mounting molecular, genetic, and clinical evidence suggests that a majority of HGS-OvCa arises from the fallopian tube (FT) epithelium (4, 6-8, 24-27), which is composed of secretory and ciliated cells (28). Although dysplastic secretory epithelial cells had been reported in the FTs of $B R C A$ mutation carriers as early as $2001(24,29)$, it was the development of the SEE-FIM (sectioning and extensively examining the fimbria) protocol (8) that led to the reproducible identification of HGS-OvCa precursors in the fimbriated end of the FT (30-32). Specifically, the careful examination of FTs from BRCA mutation carriers led to the following observations: (a) approximately $5 \%$ to $10 \%$ of $B R C A 1$ mutation carriers undergoing prophylactic surgery will have an early lesion, termed serous tubal intraepithelial carcinoma (STIC), in their FT fimbria; (b) greater than $50 \%$ of women with stage III/IV pelvic serous cancer also harbor a STIC (7); (c) identical TP53 mutations have been identified in STICs and corresponding serous carcinomas; (d) nonneoplastic FT 
secretory cells and serous carcinoma share similar morphological, immunophenotypic, and transcriptomic features $(7,8,33)$; and (e) a candidate nonmalignant precursor lesion (the p53 signature), composed of benign-appearing FT secretory cells that harbor DNA damage and TP53 mutations, has been described in the FT epithelium (33). The p53 signature is equally common in the nonneoplastic fimbria of both $B R C A$ mutation carriers and control subjects, suggesting that it is a phenomenon related to physiological stress rather than genetic risk (34). In addition, the p53 signature occurs more frequently in fimbriae that harbor a STIC and, when they co-occur, they share evidence of DNA damage and exhibit identical TP53 mutations. These observations suggest that pelvic serous carcinomas previously assigned to different sites of origin (ovary, FT, or peritoneum) share a common carcinogenic pathway not previously appreciated, which originates in the FT secretory epithelial cell. Experimental model systems, including novel genetically engineered animal models (35-37) and cell-based assays (38-40), have provided robust support for this new paradigm of ovarian cancer pathogenesis.

Because TP53 mutation represents the first genetic alteration associated with HGS-OvCa, it is of significant interest to examine the effects of mutant p53 expression in human FT epithelial cells; however, such investigations have been hampered due to the lack of culture systems that support continuous growth of these cells without transforming oncogenes, e.g., HPV E6/E7, HRAS, and SV40 T antigens (39, 40). We recently reported the development of a medium (WIT-Fo) that supports continuous growth of nonciliated human FT cells expressing human telomerase (TERT) (26). These cells, referred to as FT nonciliated epithelial (FNE) cells, are similar in phenotype to FT secretory cells (38) and express the secretory FT epithelium transcription factor PAX8. We have utilized these cultures in multiple live-cell video microscopy assays to examine the phenotypic alterations induced by expression of various mutant p53 proteins associated with ovarian and other cancers. These assays were designed to assess the ability of mutant p53 to induce phenotypic alterations associated with HGS-OvCa dissemination, including survival following dissociation from matrix attachment, cell clustering in suspension, and intercalation of cell clusters into mesothelial monolayers.

These studies demonstrate that expression of stabilized mutant p53 variants (R175H, R249S, or $\mathrm{R} 273 \mathrm{H}$ ), but not loss of expression of p53, promotes the survival and cell-cell adhesion of FNE cells under conditions mimicking peritoneal suspension, leading to the formation of multicellular clusters with mesothelial-clearing capability. These effects are dependent on engagement of integrin receptors and mesenchyme transcription factor expression. Analysis of human HGS-OvCa ascites samples provides evidence for the relevance of this effect in human tumors. Taken together, our results suggest a model in which the cell-of-origin of HGS-OvCa acquires transformed phenotypes through mutant p53-dependent mesenchymal transition and autocrine production/deposition of fibronectin.

\section{Results}

Mutant p53 promotes survival of detached FNE cells. Ovarian carcinoma cells acquire the ability to survive under anchorage deprivation conditions associated with the fluidic environment of the peritoneal cavity. To examine whether expression of mutant p53 (m-p53) variants promotes survival of FNE cells under matrix-detached conditions, we ectopically expressed $\mathrm{p} 53^{\mathrm{R} 175 \mathrm{H}}, \mathrm{p} 53^{\mathrm{R} 249 \mathrm{~S}}$, or $\mathrm{p} 53^{\mathrm{R} 273 \mathrm{H}}$, stabilized m-p53 variants associated with HGS-OvCa (Supplemental Figure 1A; supplemental material available online with this article; doi:10.1172/jci.insight.86829DS1). The expression of m-p53 ${ }^{\mathrm{R} 175 \mathrm{H}}$, for example, was comparable to the endogenous levels of m-p53 ${ }^{\mathrm{R} 175 \mathrm{H}}$ expressed in HGS-OvCa cells (Supplemental Figure 1A), indicating that the engineered FNE cells recapitulate the m-p53 protein expression observed in tumor cells. We next monitored viability of the various FNE cells in real time using live-cell video microscopy. In contrast to control FNE cell clusters, which displayed considerable disintegration in suspension over the 120-hour observation time, the vast majority of FNE cells expressing m-p53 variants (collectively referred to as FNEm-p53 cells) remained intact (Figure 1A and Supplemental Video 1). To quantify the cell death associated with suspension culture, we engineered the FNE cell populations to express GFP and used ethidium bromide $(\mathrm{EtBr})$ to visualize dead cells. EtBr intercalation into DNA occurs as a result of nuclear membrane fracture associated with cell death (Figure 1B). As shown in Figure 1, C-E, m-p53 expression significantly reduced the level of EtBr incorporation in 96 hours of suspension culture as compared to control FNE cells transduced with empty vectors. To visualize the kinetics of FNE cell death after detachment, we used time-lapse imaging of EtBr incorporation. Control cells began to incorporate EtBr 48 hours after detachment, whereas FNE-m-p53 cells remained viable throughout the 96-hour recording time (Supplemental 
A

$48 \mathrm{~h}$

$72 \mathrm{~h}$ $120 \mathrm{~h}$

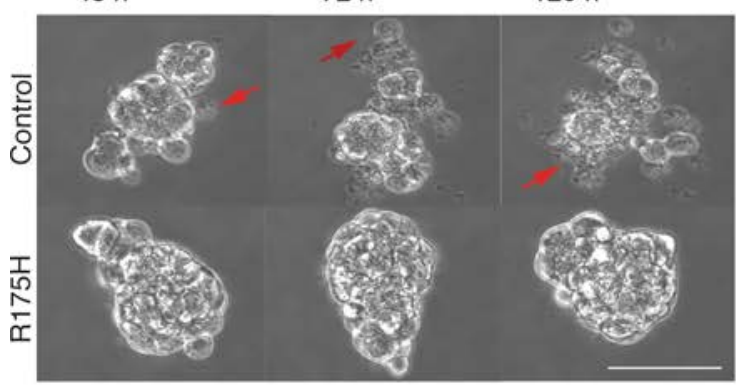

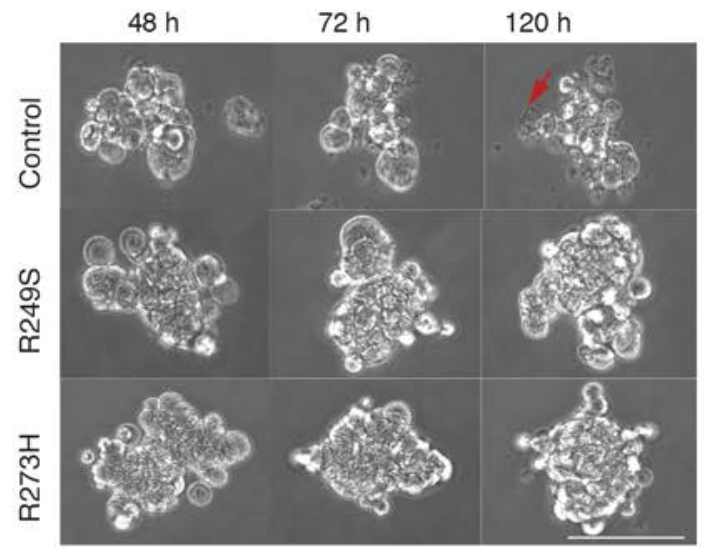

B 100 GFP positive cells

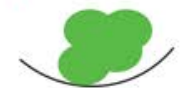

low adhesion well

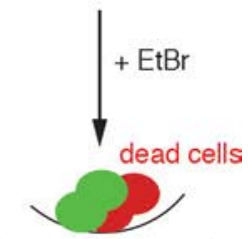

low adhesion well

\section{C}

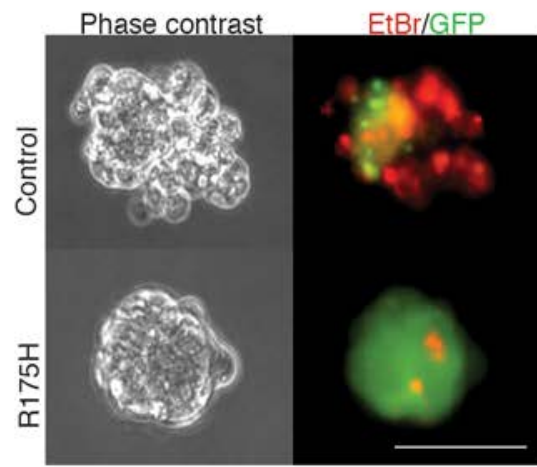

D

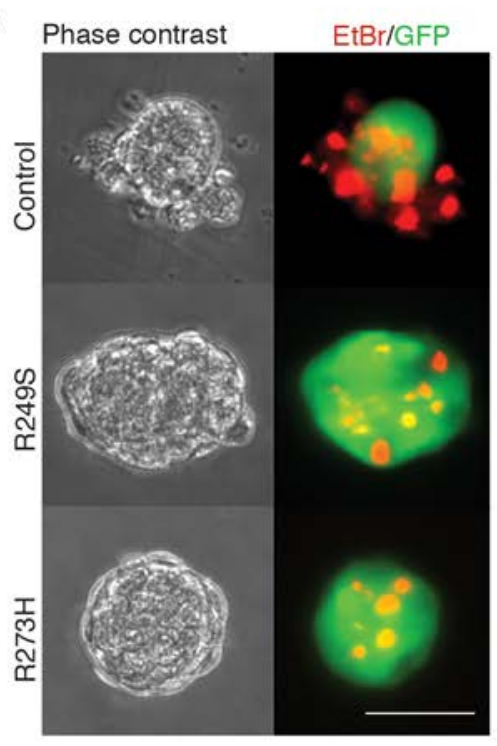

E
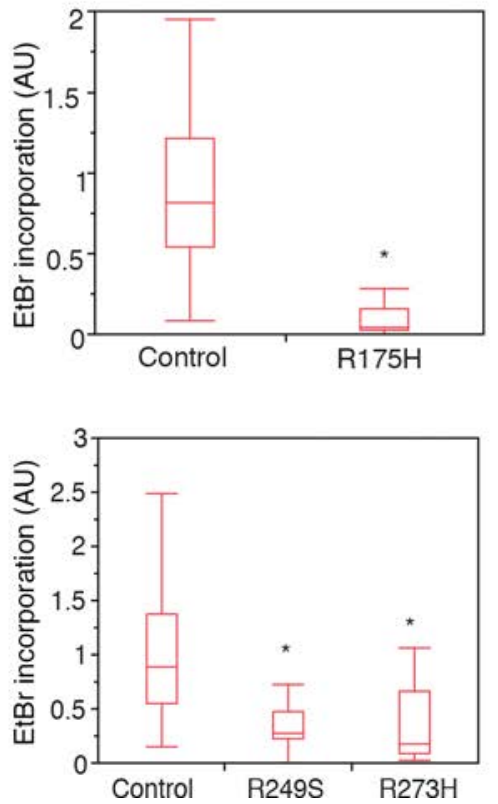

Figure 1. Mutant p53 promotes survival of detached fallopian tube nonciliated epithelial (FNE) cells. (A) Montage of representative ( $n=8-10 / g r o u p)$ phase-contrast video clips from time-lapse recording of FNE cells transduced with empty vector or mutant p53 (m-p53) variants (R175H, R249S, or R273H) and maintained in suspension for the indicated time. Arrows point to dying cells. Clips are representative of 8-10 movies per condition with 100-150 cells per movie acquired during one recording session (Supplemental Video 1). (B) Schematic depiction of the ethidium bromide (EtBr) incorporation assay used to quantify cell death (red) within multicellular clusters (green) grown in suspension. (C and D) Representative ( $n=3-4$ experiments) phase-contrast and pseudocolored fluorescence images documenting the level of EtBr incorporation into GFP-labeled FNE vector control (pWZL in C, pLenti 6 in $\mathbf{D}$ ) or FNEm-p53 (R175H, R249S, and R273H) cellular clusters maintained in suspension for 96 hours. (E) Quantification of the EtBr incorporation distribution in cell clusters from $4(\mathrm{R} 175 \mathrm{H})$ and $3\left(\mathrm{R} 249 \mathrm{~S}\right.$ and $\mathrm{R} 273 \mathrm{H}$ ) independent experiments. $n=50-60$ cellular clusters in control and $\mathrm{m}-\mathrm{p} 53^{\mathrm{R} 175 \mathrm{H}}$ groups, and $n=61,42$, and 30 cellular clusters in control, $\mathrm{m}-\mathrm{p} 53^{\mathrm{R} 2495}$, and $\mathrm{m}-\mathrm{p} 53^{\mathrm{R} 273 \mathrm{H}}$ groups, respectively. Each cluster contained 100-150 cells. Scale bar: $150 \mu \mathrm{m}$. All data shown as the median (horizontal bar), interquartile range (box), and minimum/maximum values (whiskers). Statistical analysis was performed using either 2-tailed Student's $t$ test or 1-way ANOVA and post-hoc Tukey-Kramer test. ${ }^{*} P<0.05$ for each $p 53$ mutant cell line relative to the vector control.

Figure 1B and Supplemental Video 2). These results indicate that m-p53 expression promotes anchorageindependent survival of FNE cells.

m-p53 promotes survival of detached cells independently of cell-cell adhesion. In ovarian cancer patients, carcinoma cells residing within peritoneal fluids adhere to each other and form multicellular suspended cell clusters $(41,42)$ (Figure 2A). Similarly in our model, we observed that within a 24-hour period, FNE-m-p53 cells, but not control cells, formed compacted cell clusters in suspension (Figure 2A and Supplemental Figure $2 \mathrm{~A}$ ), raising the possibility that $\mathrm{m}$-p 53 expression promotes cell-cell adhesion. To determine if expression of m-p53 promotes cell-cell adhesion that contributes to the assembly of the compacted multicellular FNE 
A

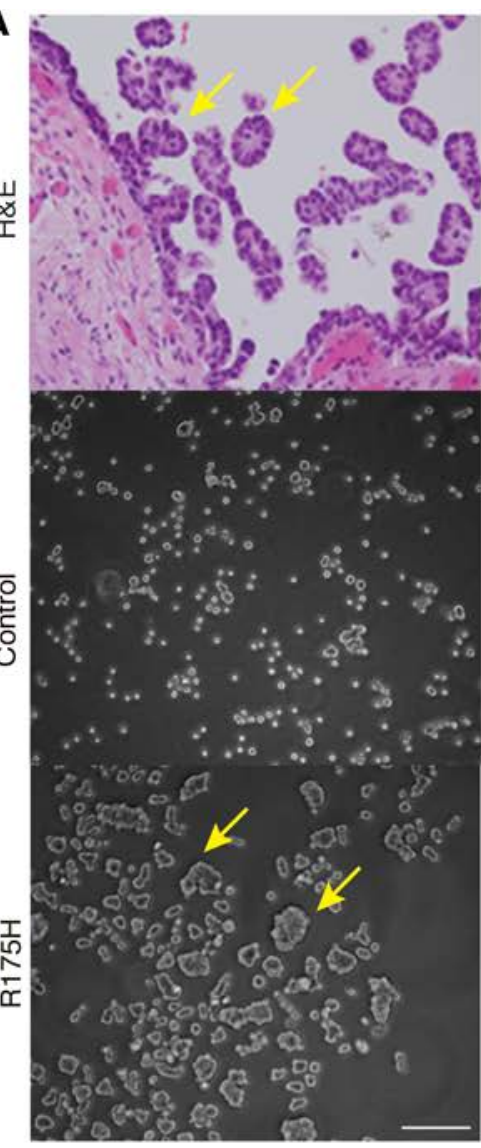

D

PDMS non-adherent micro patterned culture dish
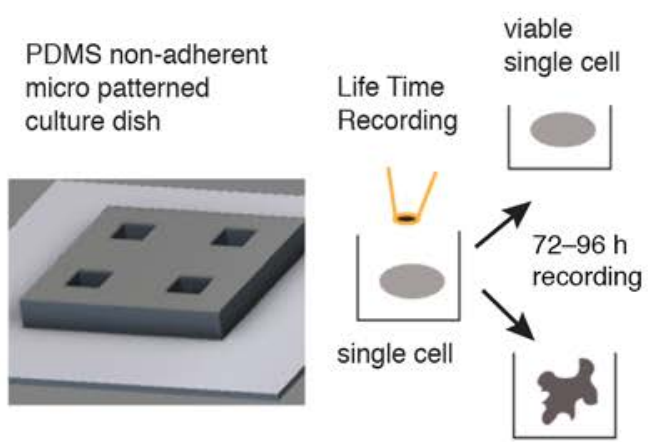

single cell dies

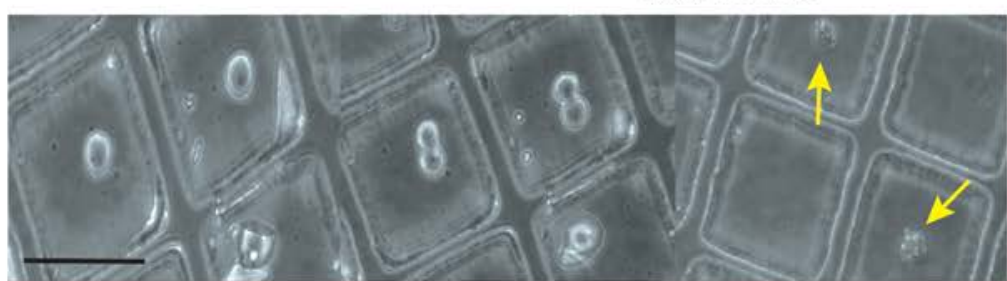

Alive not divided

C

B
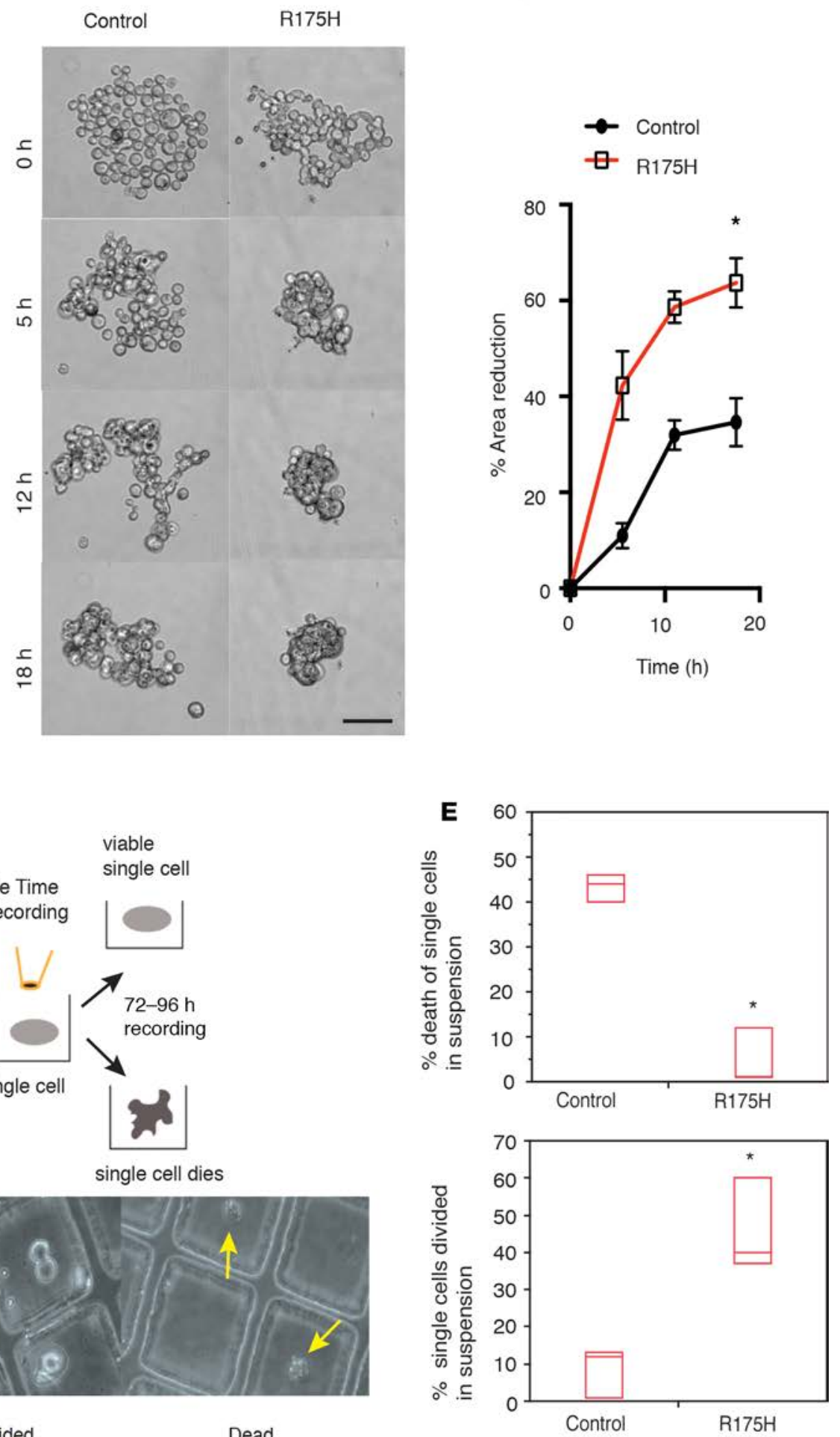
Figure 2. Mutant $\mathrm{p5} 3^{\mathrm{R} 175 \mathrm{H}}$ ( $\mathrm{m}-\mathrm{p} 53^{\mathrm{R} 175 \mathrm{H}}$ ) promotes survival of detached fallopian tube nonciliated epithelial (FNE) cells independently of cell-cell adhesion. (A) H\&E staining of disseminating carcinoma cell clusters from the fallopian tube (upper) and phase-contrast images of control and FNE-m-p53 ${ }^{\text {R175H }}$ cells cultured in suspension for 24 hours. Arrows point to detached carcinoma cells from the surface of fimbriae (upper), and to compacted FNE-m-p53 ${ }^{\text {R175H }}$ cells. Scale bar: $300 \mu \mathrm{m}$. (B) Representative ( $n=8$ videos) video clips of control and FNE-m-p53 ${ }^{\mathrm{R} 175 \mathrm{H}}$ cells cultured in suspension for the indicated times from Supplemental Video 3. Eight movies were recorded per cell type. Scale bar: $150 \mu \mathrm{m}$. (C) Representative time course of the percentage reduction in cell cluster area in suspension for control and FNE-m-p53 ${ }^{\mathrm{R} 175 \mathrm{H}}$ cells. $n=8$ cell clusters scored per condition. Data shown as the mean $\pm \mathrm{SEM}$. The percentage reduction in cell area at the latest time point was measured in 3 independent experiments on $n=29$ control and $n=31 \mathrm{FNE}-\mathrm{m}$-p53 ${ }^{\mathrm{R} 175 \mathrm{H}}$ cellular clusters. Each cellular cluster contained 100-150 cells. (D) Upper panel: Schematic depiction of the microscopy-based detached-single-cell assay. Lower panel: Representative phase-contrast images of the outcomes observed following culture of single cells in suspension for 72 hours (Supplemental Video 4 ). Scale bar: $100 \mu \mathrm{m}$. (E) Quantification of single-cell death (upper panel) or proliferation (lower panel) in suspension for 72 hours. This experiment was repeated 3 times with $n=50-70$ single cells analyzed per condition per experiment. Data shown as the median (horizontal bar), interquartile range (box), and minimum/maximum values (whiskers). Statistical analysis performed using 2-tailed Student's $t$ test. ${ }^{*} P<0.05$.

cell clusters in suspension, we developed a live-cell microscopy-based assay to monitor and quantify cell aggregation in real time and space (see Methods). FNE-m-p53 cells displayed a significantly greater propensity to form compacted cell clusters in suspension, as measured by the percentage decrease of the cell cluster area over time (Figure 2, B and C, Supplemental Figure 2B, and Supplemental Video 3).

To directly test whether the m-p53-mediated enhanced cell-cell adhesion is critical for survival in suspension, we developed a culture substrate-patterning method that allowed us to follow the fate of single cells in suspension by monitoring cellular disintegration and EtBr incorporation with live microscopy (Figure 2D). We found that a significantly lower percentage of FNE-m-p53 cells disintegrated and incorporated EtBr under single-cell culture conditions compared to control FNE cells (Figure 2E, Supplemental Figure 2C, and Supplemental Videos 4 and 5). In addition, a significant number of single FNE-mp53 cells, but not control cells, divided in suspension (Figure 2E). These results demonstrate that $\mathrm{m}$-p53 promotes survival of FNE cells independently of cell-cell adhesion.

m-p53 promotes mesothelial clearance. HGS-OvCa cell clusters or single cells disseminate within the peritoneal cavity by attaching to and intercalating into the superficial mesothelial cell layer. Expression of $\mathrm{m}$-p53 has been shown to mediate adhesion of cancer cells to mesothelioma cell monolayers (43), raising the possibility that it may also play a role in mesothelial clearance in our FNE model system. Using a livecell microscopy-based assay that we previously described (21), we examined whether expression of m-p53 in FNE cells was sufficient to enhance intercalation into a mesothelial monolayer in culture. We found that all FNE cellular clusters were able to adhere to the mesothelial monolayer, but only the FNE-m-p53 lines were able to subsequently clear the monolayer within the 8 hours of observation time (Figure 3, A-D, and Supplemental Video 6). These data indicate that expression of p53 mutant variants is sufficient to promote mesothelial clearance.

m-p53-induced phenotypes represent gain-of-function activities. Overexpressed stabilized $\mathrm{m}$-p53 proteins bind to and inhibit wild-type p53 function (44). However, ectopically expressed m-p53 can also promote gain-offunction (GOF) activities through protein-protein interactions or through binding to specific gene promoters (45-48). To determine the extent to which loss of p53 function contributes to the phenotypes associated with m-p53 expression, we used shRNAs to knock down endogenous p53 expression in FNE cells. Loss of p53 function was confirmed by reduction in both p53 protein and CDKN1A mRNA levels (Supplemental Figure $3 \mathrm{~A}$ ). We found that knockdown of p53 had no effect on cellular cluster disintegration and EtBr incorporation relative to control FNE cells and in contrast to the effects of $\mathrm{m}$-p5 $3^{\mathrm{R} 175 \mathrm{H}}$ overexpression (Figure 4, A-C, Supplemental Figure 3, B and C, and Supplemental Videos 7 and 8). Moreover, knockdown of endogenous wild-type p53 expression in FNE cells did not promote mesothelial clearance (Figure 4, D and $\mathrm{E}$ ). These data indicate that loss of wild-type $\mathrm{p} 53$ function is not sufficient to phenocopy $\mathrm{m}$-p 53 expression in these assays, suggesting that $\mathrm{m}$-p53 regulates additional molecular programs that confer the FNE phenotypes described here.

Integrin $\alpha 5 \beta 1$ is required for $m-p 53-$ mediated anchorage independence. Previous work from our group revealed that integrin $\alpha 5 \beta 1$ plays a critical role in ovarian carcinoma mesothelial intercalation (21), and $\alpha 5 \beta 1$ fibronectin interactions have been implicated in cell-cell adhesion of OVCAR5 ovarian carcinoma cells (42). In addition, integrin $\alpha 5 \beta 1$ has been shown to mediate anchorage-independent survival of ERBB2transformed mammary epithelial cells (49). We observed that m-p53 induced the expression of integrins $\alpha 5$ and $\beta 1$ in FNE cultures (Figure $5 \mathrm{~A}$ ). These findings led us to examine whether $\alpha 5 \beta 1$ is involved in the mechanism by which $\mathrm{m}$-p53 confers anchorage independence. We assessed the effects of blocking integrin 
A $0.5 \mathrm{~h}$

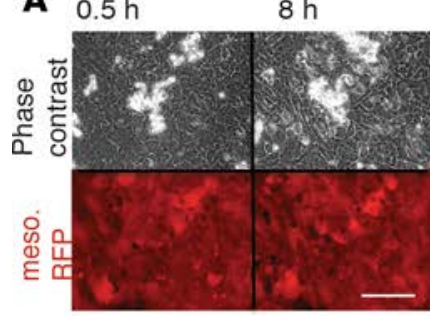

Control

C

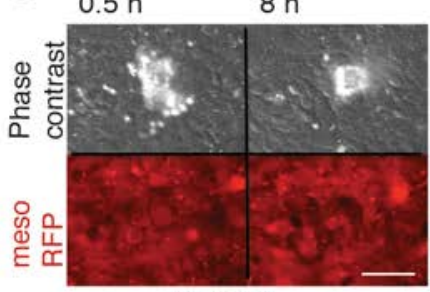

Control

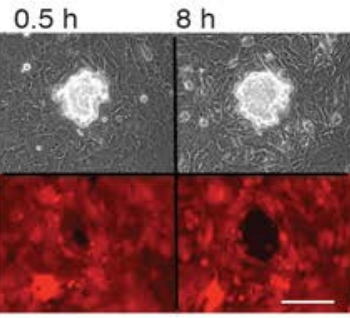

$\mathrm{R} 175 \mathrm{H}$

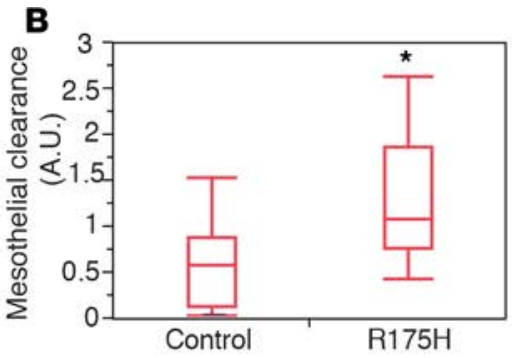

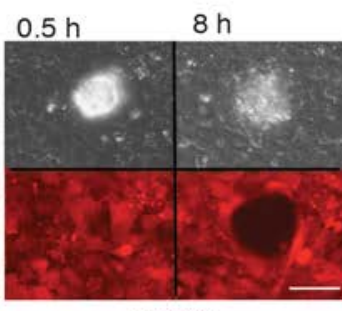

R249S

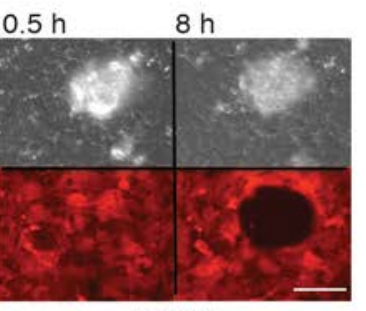

$\mathrm{R} 273 \mathrm{H}$

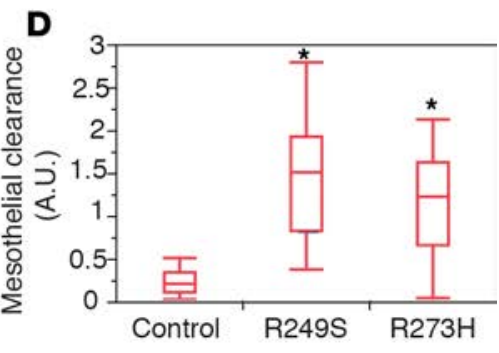

Figure 3. Mutant p53 (m-p53) promotes mesothelial clearance. (A and C) Phase-contrast and pseudocolored (red) fluorescence images of the ability of control fallopian tube nonciliated epithelial (FNE) cells and FNE-m-p53 cell clusters to clear the mesothelium (mesothelial cells expressing red fluorescent protein [RFP]) at the indicated time points (Supplemental Video 6). Scale bar: $150 \mu \mathrm{m}$. (B and D) Quantification of the mesothelial clearance distribution by the various FNE cell lines from a representative experiment. This experiment was repeated 3 times with $n=10$ control, $n=6 \mathrm{~m}-\mathrm{p} 53^{\mathrm{R} 175 \mathrm{H}}, n=10$ $\mathrm{m}-\mathrm{p} 53^{\mathrm{R} 249 \mathrm{~S}}$, and $n=10 \mathrm{~m}-\mathrm{p} 53^{\mathrm{R} 273 \mathrm{H}}$ cell clusters scored per experiment. All data shown as the median (horizontal bar), interquartile range (box), and minimum/maximum values (whiskers). Statistical analysis was performed using either 2-tailed Student's $t$ test $\left(\mathbf{B},{ }^{*} P<0.05\right)$ or 1 -way ANOVA and post-hoc Tukey-Kramer test ( $\mathbf{D},{ }^{*} P<0.05$ for each engineered FNE cell line relative to its control).

$\alpha 5$ or $\beta 1$ function on the survival of FNE-m-p53 ${ }^{\mathrm{R} 175 \mathrm{H}}$ cells or a human tumor line derived from peritoneal ascites from a patient with HGS-OvCa (DF30) that endogenously expresses m-p53 ${ }^{\mathrm{R} 175 \mathrm{H}}$ and integrin $\alpha 5 \beta 1$ (Supplemental Figure 3D). We incubated FNE-m-p53 ${ }^{\mathrm{R} 175 \mathrm{H}}$ or DF30 cells with integrin $\alpha 5$ - or $\beta 1$-blocking antibodies that we previously reported to inhibit mesothelial intercalation (21). Function-blocking antibodies against N-cadherin (50-52) and MUC16 (53), two surface molecules expressed in FNE-m-p53 and DF30 cells (Supplemental Figure 3, E and F), were included as controls. We observed that incubation with blocking antibodies against either $\alpha 5$ or $\beta 1$ integrin, but not N-cadherin or MUC16, had an effect on cellular cohesion (Figure 5A and Supplemental Video 9, A and B) and increased EtBr incorporation in a dose-dependent manner in both FNE-m-p53 ${ }^{\mathrm{R} 175 \mathrm{H}}$ and DF30 cells (Figure 5, B-E, Supplemental Figure 4, $\mathrm{A}$ and $\mathrm{B}$, and Supplemental Video 10). These data suggest that m-p53-mediated survival in suspension is dependent on the engagement of $\alpha 5 \beta 1$ integrin.

$m$-p53 promotes fibronectin secretion and mesenchymal transcription. Since we cultured FNE cells in the absence of exogenous fibronectin (Figure 5A and Supplemental Figure 4A), the ligand for integrin $\alpha 5 \beta 1$, we reasoned that fibronectin was produced by FNE cells. To examine this possibility, we addressed whether m-p53 promotes production of fibronectin in FNE cells cultured in suspension. Indeed, we found that detached FNE-m-p53 cells displayed increased fibronectin protein expression and secretion into the media when compared to either control or FNE cells depleted of wild-type p53 (referred to as FNE-p53shRNA cells) (Figure 6A and Supplemental Figure 4C). These results indicate that increased fibronectin production represents a GOF phenotype induced by m-p53. In addition, siRNA-mediated fibronectin attenuation significantly reduced FNE-m-p53 ${ }^{\mathrm{R} 175 \mathrm{H}}$ cell cluster survival in suspension (Supplemental Figure 4, D and E), providing supportive evidence for a role of endogenous fibronectin in anchorage-independent survival of FNE-m-p53 ${ }^{\mathrm{R} 175 \mathrm{H}}$ cells

To examine fibronectin localization in FNE cells cultured in suspension, we immunostained fixed and nonpermeabilized suspended cell clusters composed of the various FNE cell lines with an antibody recognizing human fibronectin. As shown in Figure 6B, more fibronectin deposition was detected on the surface of FNE-m-p53 cells as compared to control or FNE-p53shRNA cells. High pixel density confocal analysis of nonpermeabilized cells revealed that fibronectin localized to intercellular junctions within cellular aggregates, at adhesion plaques that contained activated $\beta 1$ integrin. Fibronectin and activated $\beta 1$ integrin were 


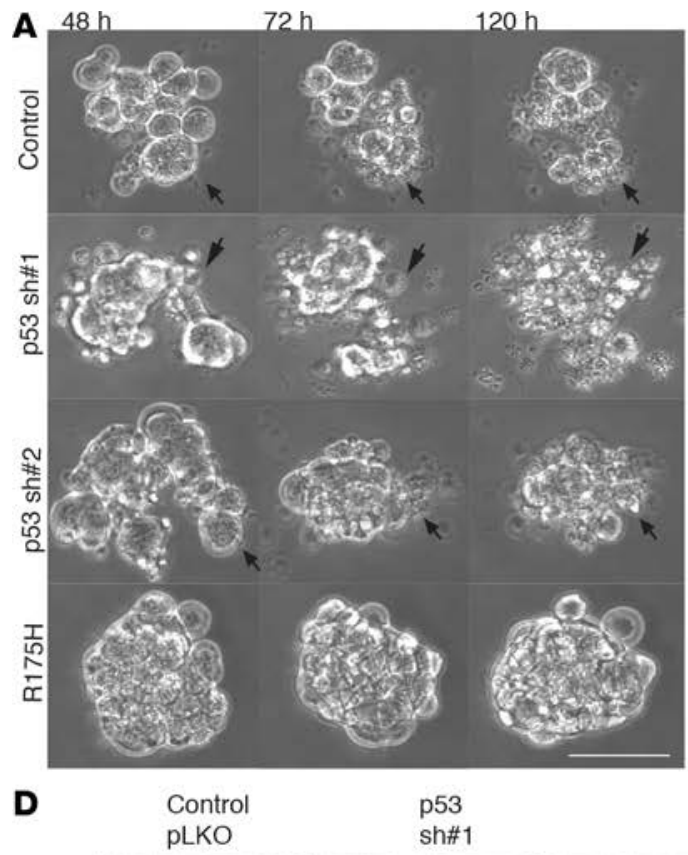

B

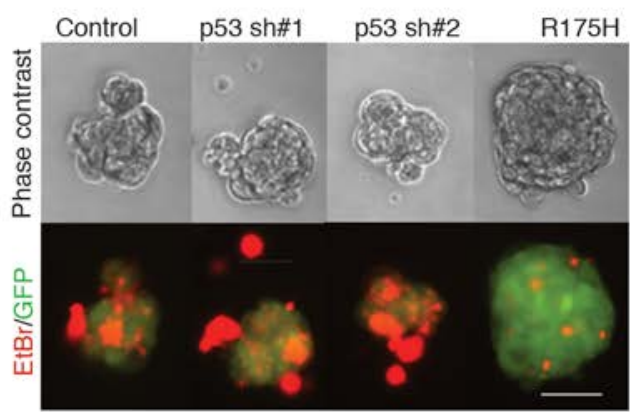

C

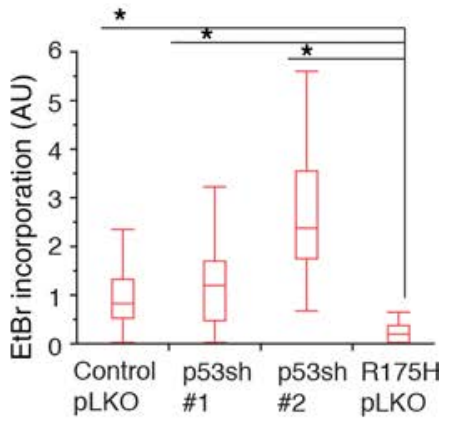

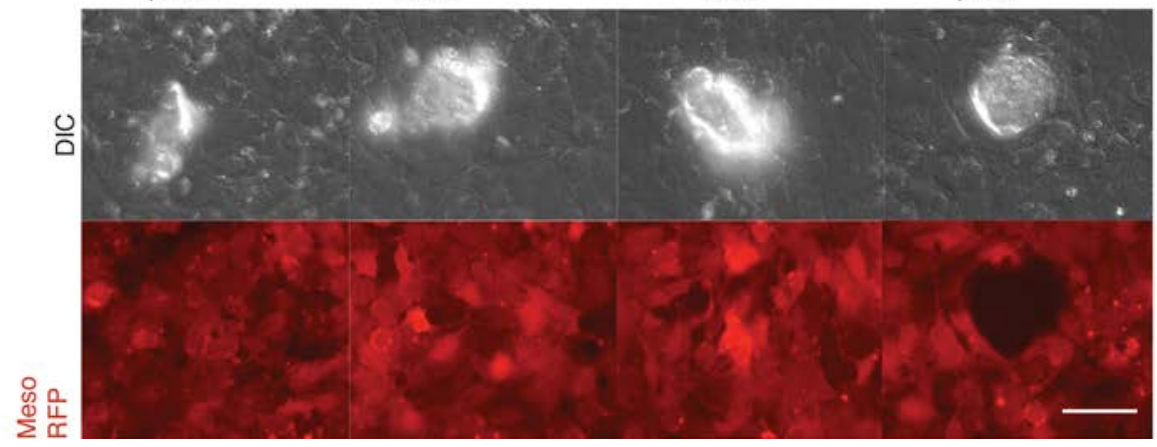

\section{$\mathbf{E}$}

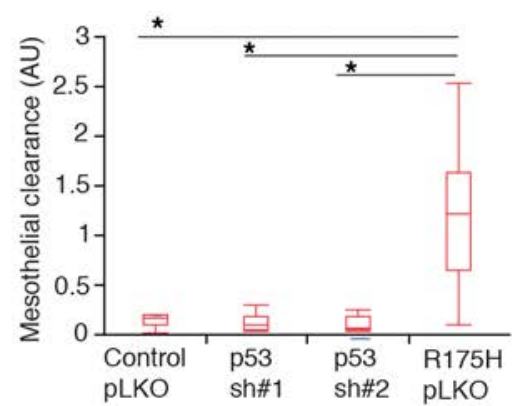

Figure 4. shRNA-mediated attenuation of wild-type p53 does not induce phenotypes associated with mutant p53 (m-p53) overexpression. (A) Representative phase-contrast video clips of fallopian tube nonciliated epithelial (FNE) cells transduced with empty vector (pLKO), p53shRNA\#1, p53shRNA\#2, or m-p53 $3^{\mathrm{R} 175 \mathrm{H}}$ plus empty pLKO (Supplemental Video 7) and cultured in suspension for the indicated time points. Arrows point to dying cells. Clips are representative of 10 movies per condition with 100-150 cells imaged per movie, acquired in 1 recording session. (B) Phase-contrast and pseudocolored fluorescence images representing the degree of ethidium bromide (EtBr; red) incorporation into cellular clusters (green). (C) Quantification of the distribution of EtBr incorporation among the various FNE suspended cell clusters. Three independent experiments performed with $n=39$ (control), $n=33$ (p53shRNA\#1), $n=29$ (p53shRNA\#2), and $n=33$ (m-p53 ${ }^{\mathrm{R} 175 \mathrm{H}}$ ) cellular clusters analyzed. (D) Representative differential interference contrast (DIC) and pseudocolored (red) fluorescence images demonstrating the ability of control (pLKO), p53shRNA\#1, p53shRNA\#2, and m-p53 ${ }^{\text {R175H }}$ FNE cell clusters to clear the mesothelium (mesothelial cells expressing red fluorescent protein [RFP]), 8 hours after seeding. (E) Quantification of the mesothelial clearance distribution by the various FNE cell lines from a representative experiment. This experiment was repeated twice with $n=7-8$ cellular clusters analyzed per condition. All data shown as the median (horizontal bar), interquartile range (box), and minimum/maximum values (whiskers). Statistical analysis performed using 1-way ANOVA and post-hoc Tukey-Kramer tests comparing $\mathrm{m}$-p $53^{\mathrm{R} 175 \mathrm{H}}$ with each group (control pLKO, p53sh\#1, and p53sh\#2). ${ }^{*} P<0.05$. Scale bar: $150 \mu \mathrm{m}$.

also detected on the nonjunctional surface of cell clusters (Figure 6C), suggesting that fibronectin deposition is not limited to areas of cell-cell contact. Taken together, these data suggest that expression of m-p53 promotes fibronectin deposition.

To further explore this possibility, we examined fibronectin expression in a panel of HGS-OvCa patientderived cells (DF14, DF216, DF59, DF30, DF106, and DF68) (22) cultured in suspension for 120 hours. We observed that DF samples that expressed a stabilized m-p53 variant (R175H or G266R) expressed fibronectin; however, fibronectin expression was also detected in one DF sample that harbored a nonsense p53 mutation (V122X) (Figure 6D), suggesting that fibronectin expression in patient-derived human HGS$\mathrm{OvCa}$ cells is associated with expression of stabilized mutant $\mathrm{p} 53$ proteins, but is not exclusively regulated by such mutants. We also found that fibronectin expression inversely correlated with E-cadherin expression in the DF tumor lines (Figure 6D) and in various ovarian cancer cell lines (Supplemental Figure 4F), 

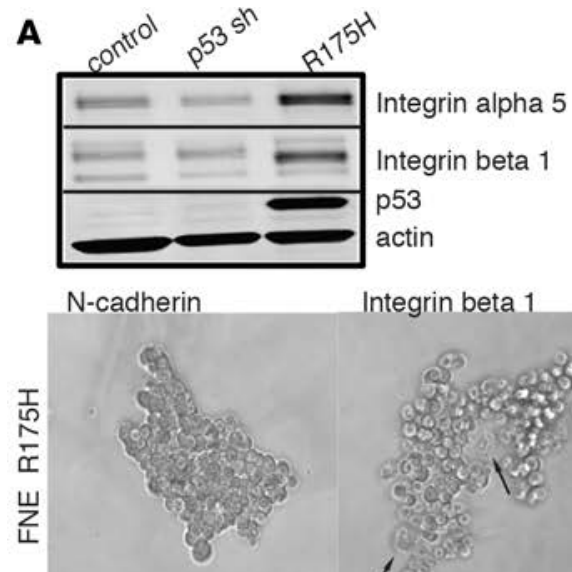
Integrin beta 1
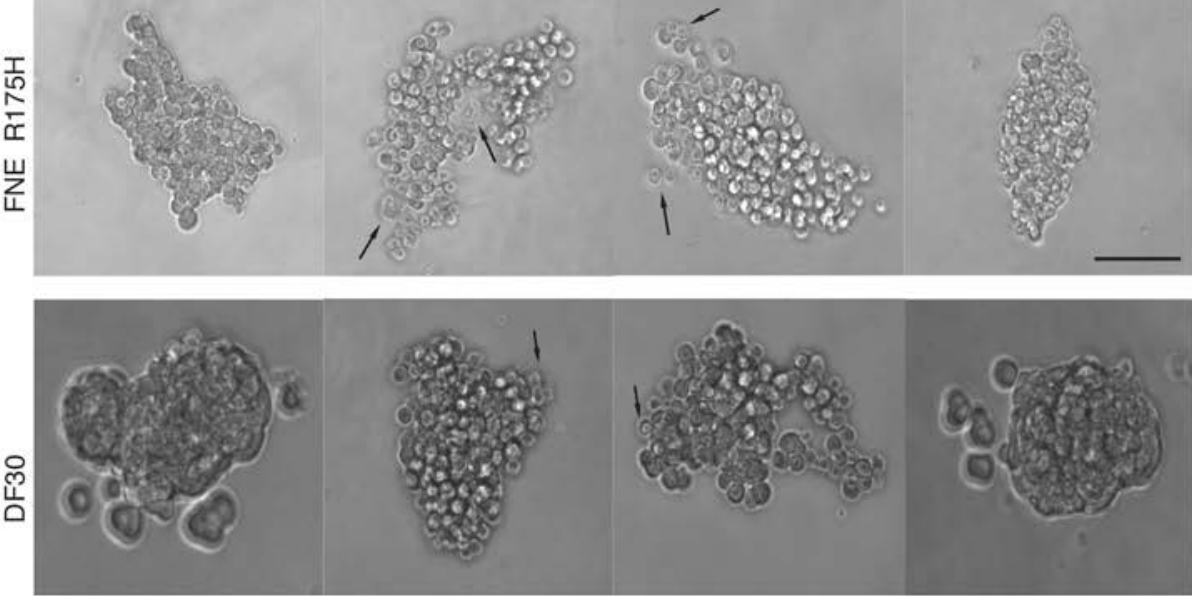

C
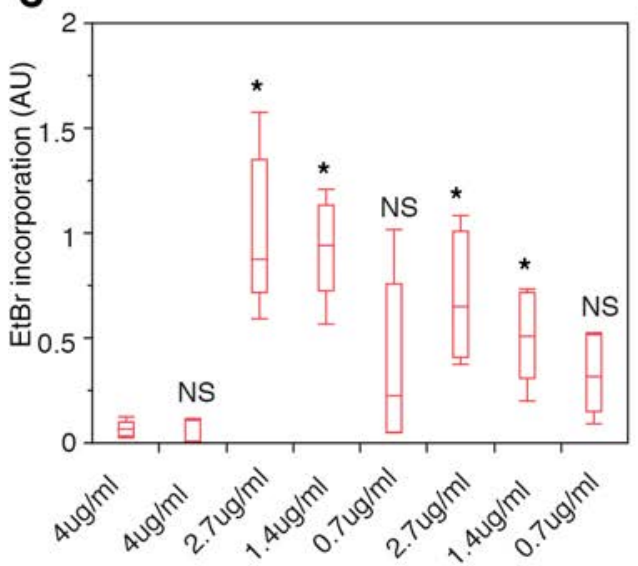

D

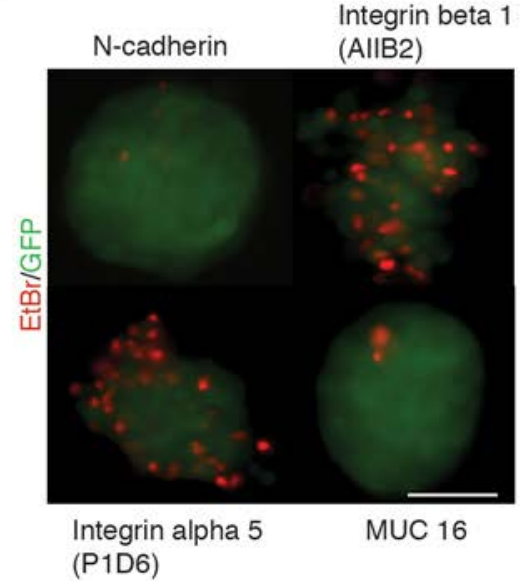

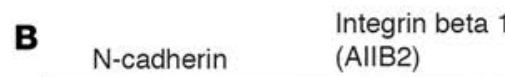

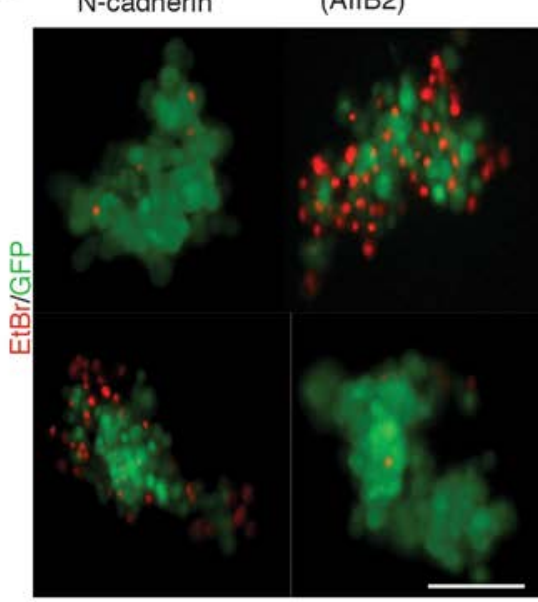

Integrin

Integrin alpha 5
E (P1D6)

MUC 16

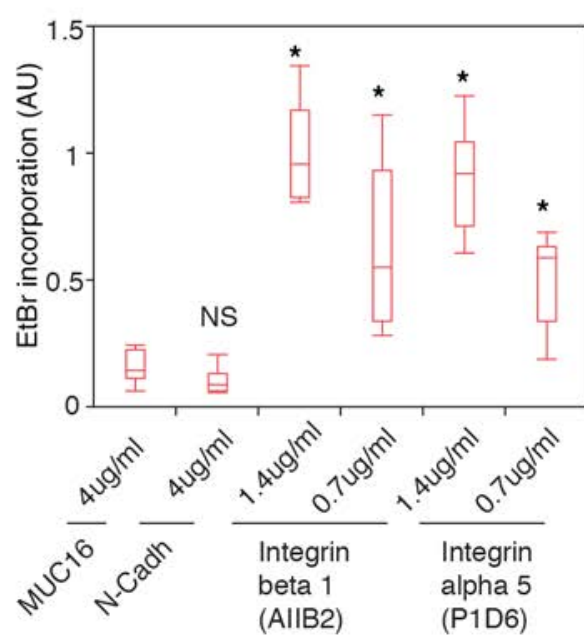

Figure 5. Integrin $\alpha \mathbf{5} \beta \mathbf{1}$ supports mutant p53 (m-p53)-induced survival under detached conditions. (A) Upper panel: Western blots of integrin $\alpha 5$, integrin $\beta 1, p 53$, and actin expression in the various fallopian tube nonciliated epithelial (FNE) cell lines. Three independent experiments were performed. Lower panel: Representative video clips ( $n=5 /$ condition) of FNE-m-p53 ${ }^{\mathrm{R} 175 \mathrm{H}}$ or DF30 cell clusters treated with the indicated function-blocking Abs and cultured in serum/EGF-free medium in suspension for 24 hours (Supplemental Video 9, $\mathbf{A}$ and B). Arrows point to dying cells. Five movies were recorded per cell type with 100-150 cells per movie. Scale bar: $150 \mu \mathrm{m}$. (B) Representative $(n=15)$ pseudocolored fluorescence images of ethidium bromide (EtBr) incorporation into GFP-labeled FNE-m-p53 ${ }^{\mathrm{R} 175 \mathrm{H}}$ cell clusters treated with the indicated function-blocking Abs and cultured in serum/ EGF-free medium for 48 hours. Scale bar: $100 \mu \mathrm{m}$. (C) Quantification of EtBr incorporation into FNE-mp53 ${ }^{\text {R175H }}$ cell clusters cultured in suspension in serum/EGF-free media in the presence of the indicated function-blocking Abs at the indicated concentrations. This experiment was repeated 3 times at the $2.7 \mu \mathrm{g} / \mathrm{ml}$ concentration of integrin function-blocking Abs and at the $4 \mu \mathrm{g} / \mathrm{ml}$ of mucin 16 (MUC16)- or N-cadherin-blocking Abs, with $n=5$ cell clusters scored per condition. Each cell cluster consisted of 100-150 cells. (D) Representative $(n=15)$ pseudocolored fluorescence images of EtBr incorporation into GFP-labeled DF30 cell clusters treated with the indicated concentration of function-blocking Abs and cultured in serum/EGF-free medium in suspension for 48 hours. Scale bar: $100 \mu \mathrm{m}$. (E) Quantification of EtBr incorporation into DF30 cell clusters treated with function-blocking Abs at the indicated concentrations and cultured in suspension in serum/EGF-free media for 48 hours. This experiment was repeated 3 times at the $1.4 \mu \mathrm{g} / \mathrm{ml}$ concentration of integrin-blocking Abs and at the $4 \mu \mathrm{g} / \mathrm{ml}$ of mucin 16 (MUC16)- or N-cadherin-blocking Abs with $n=5$ cell clusters analyzed per condition. Each cell cluster consisted of 100-150 cells. All data shown as the median (horizontal bar), interquartile range (box), and minimum/ maximum values (whiskers). ${ }^{*} P<0.05$ for each condition relative to the samples treated with MUC16 Ab determined by a 1-way ANOVA and post-hoc Tukey-Kramer test comparing each condition to the MUC16 control. NS, not significant difference relative to the MUC16 control. 
A
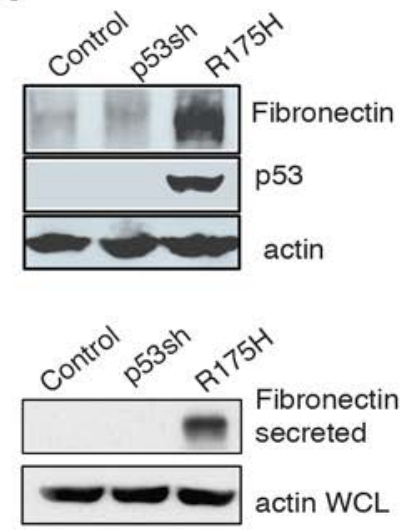

C
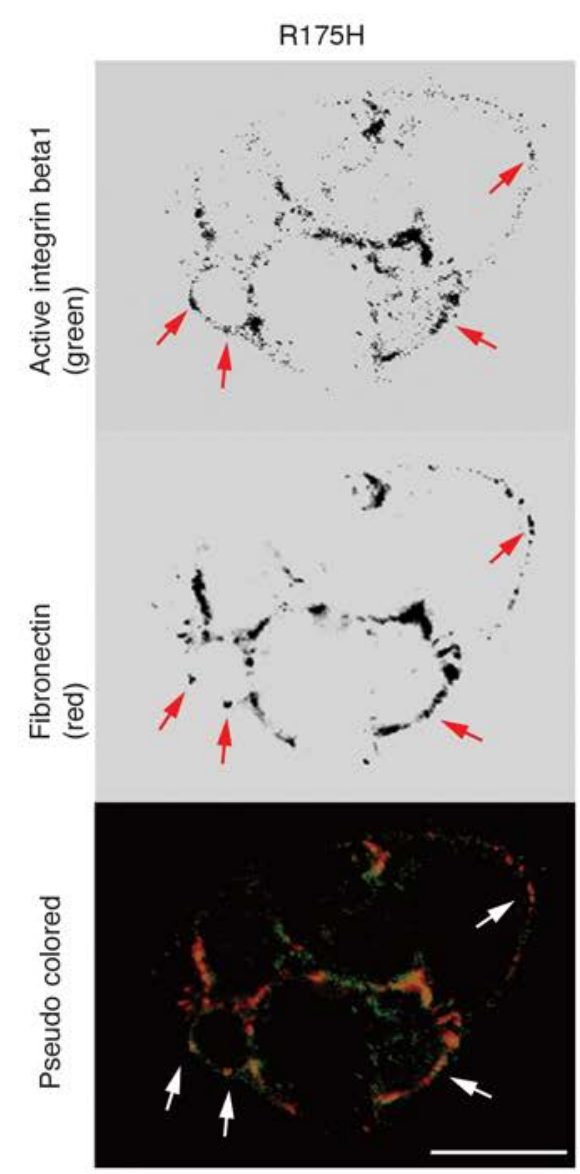
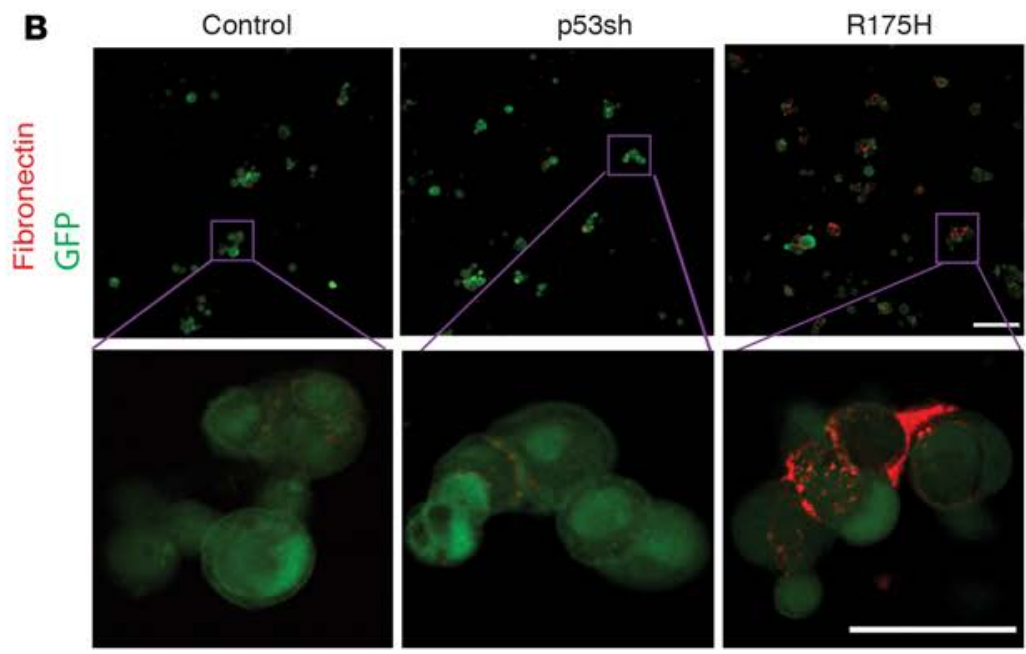

D
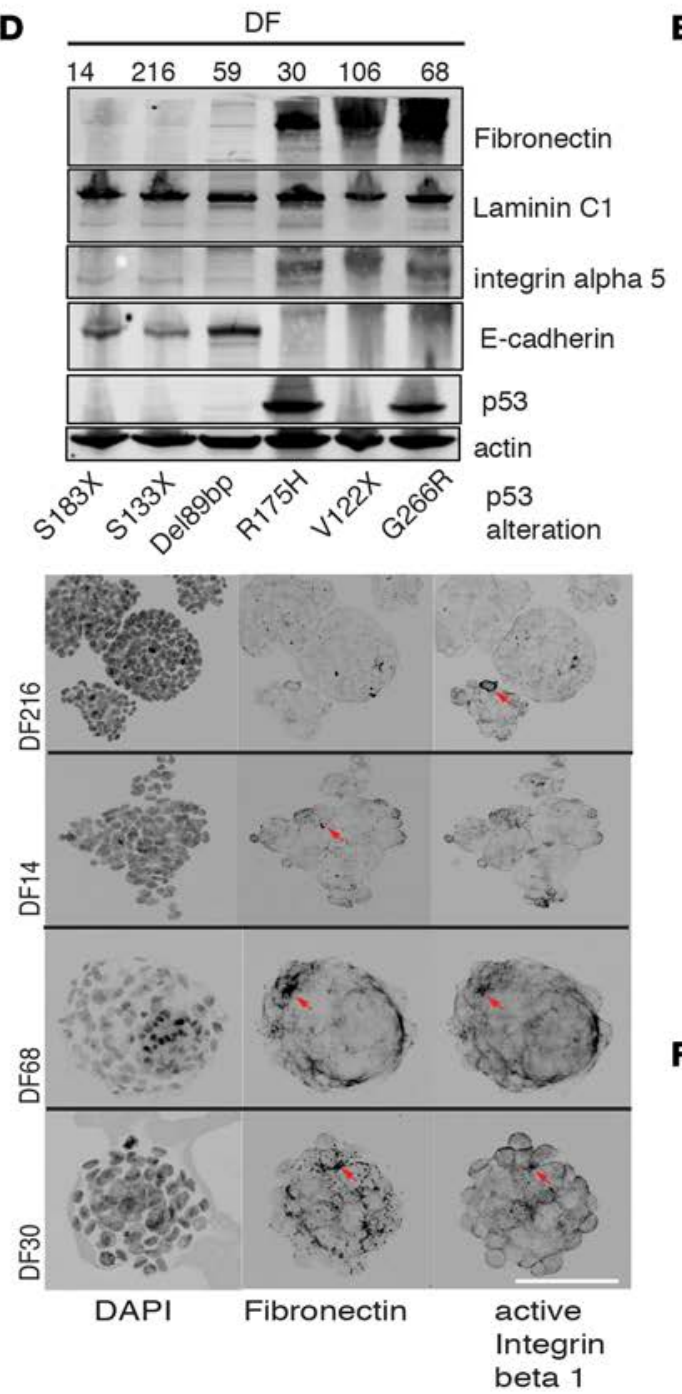
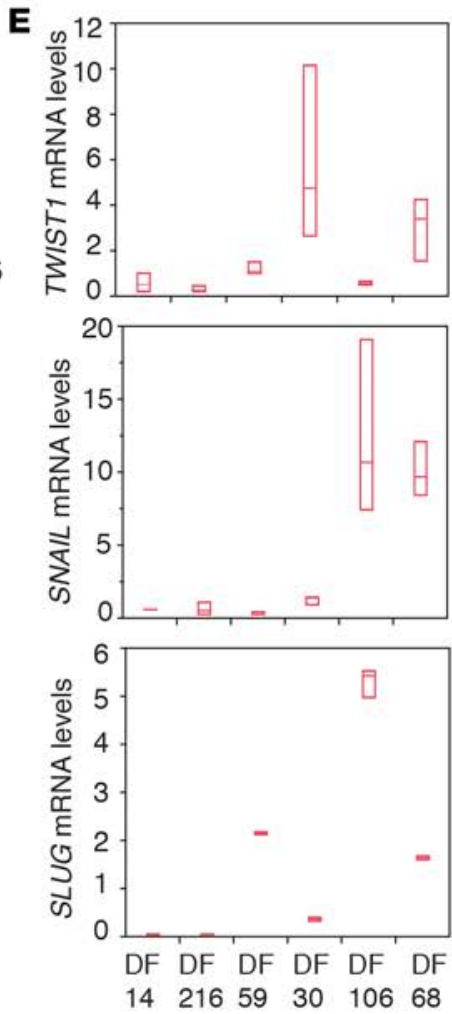

$\mathbf{F}$

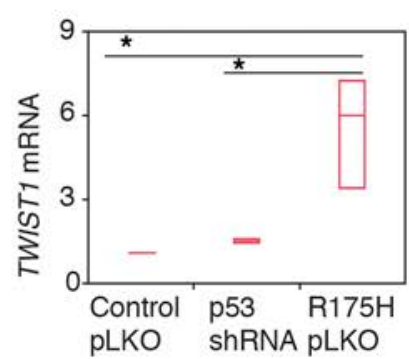


Figure 6. Mutant p53 (m-p53) promotes fibronectin secretion and mesenchymal transcription in fallopian tube nonciliated epithelial (FNE) cells. (A) Upper panel: Western blots of fibronectin, $\mathrm{p} 53$, and actin expression in FNE-m-p53 ${ }^{\mathrm{R} 175 \mathrm{H}}$ cells cultured in suspension for 24 hours. Fibronectin and actin blots were repeated 3 times. Lower panel: Western blot of secreted fibronectin from trichloroacetic acid-precipitated protein preparation from serum-free 24-hour suspension cultures of various FNE cell lines. Actin blotting was performed on whole-cell lysate. This experiment was performed twice. (B) Confocal microscopy images of fibronectin immunofluorescence staining (red) and GFP (green) in the various FNE cell lines cultured in suspension. Scale bar: 100 $\mu \mathrm{m}$. Inset shown at higher magnification. Scale bar: $50 \mu \mathrm{m}$. (C) Confocal microscopy images of integrin $\beta 1$ and fibronectin immunofluorescence staining in FNE-m-p53 ${ }^{\text {R175H }}$ cell clusters cultured in suspension for 72 hours. Scale bar 50: $\mu \mathrm{m}$. Arrows point to outer-surface localization of integrin $\beta 1$ and fibronectin. (D) Upper panel: Western blots of fibronectin, laminin C1, integrin $\alpha 5$, E-cadherin, and actin expression among various DF samples. This experiment was repeated twice. Lower panel: Confocal images of fibronectin and activated integrin $\beta 1$ immunofluorescence staining in DF cell clusters cultured in suspension for 72 hours. Arrows point to fibronectin- and active $\beta 1$ integrin-rich plaques detected on the outer cell surface. Scale bar: $150 \mu \mathrm{m}$. (E) Twist family BHLH transcription factor 1 (TWIST1), Snail family zinc finger 1 (SNAIL), and Snail family zinc finger 2 (SLUG) mRNA expression levels among the various DF cells cultured in suspension for 120 hours. This PCR reaction was repeated 3 times with 3 technical replicates. (F) TWIST1 mRNA fold change in the various FNE cells. Values are normalized to FNE control cells. All data shown as the median (horizontal bar), interquartile range (box), and minimum/maximum values (whiskers). Statistical analysis performed using 1-way ANOVA (E), or 1-way ANOVA and post-hoc Tukey-Kramer test (F). ${ }^{*} P<0.05$ comparing R175H pLKO to control pLKO or p53shRNA.

suggesting that autocrine production of fibronectin in suspension may be a molecular characteristic of ovarian cancer cells that display a mesenchymal-like phenotype.

Mutant p53 has been shown to induce mesenchymal transition (54-56).To address whether fibronectin expression correlates with a mesenchymal phenotype, we examined mRNA expression of the mesenchymal transcription factors (TFs) TWIST1, SNAIL (SNAI1), and SLUG (SNAI2) in DF tumor cells. We observed that DF cells that exhibited a high level of fibronectin and a low level of E-cadherin protein expression displayed substantially higher levels of 1 or more of the mesenchymal TFs than those with low fibronectin and high E-cadherin expression (Figure 6E). Of the patient-derived DF tumor samples, DF30 cells, which carry the stabilizing R175H mutation, displayed the highest levels of TWIST1, raising the possibility that $\mathrm{m}-\mathrm{p} 53^{\mathrm{R} 175 \mathrm{H}}$ promotes TWIST1 expression. Indeed, expression of $\mathrm{m}-\mathrm{p} 53^{\mathrm{R} 175 \mathrm{H}}$ in FNE, but not wild-type $\mathrm{p} 53$ knockdown cells, promoted TWIST1 mRNA expression (Figure 6F). In addition, we observed that ovarian cancer cell lines that express fibronectin and low levels of E-cadherin (Supplemental Figure 4F) display higher TWIST1 mRNA levels than those with low fibronectin and high E-cadherin expression (Supplemental Figure 4G). These results suggest that GOF m-p53 proteins induce mesenchymal TFs, leading to fibronectin production in FNE cells.

TWIST1 regulates $m$-p53-induced phenotypes. Given that $\mathrm{m}-\mathrm{p} 53^{\mathrm{R} 175 \mathrm{H}}$ promoted TWIST1 expression in FNE cells and has been previously implicated in the regulation of TWIST1 expression in normal prostate epithelium (48), we evaluated the effects of overexpression of TWIST1 as a representative mesenchymal TF on FNE cell survival in suspension. We were unable to derive a stable FNE cell line overexpressing TWIST1; however, ectopic expression of TWIST1 fused to the estrogen receptor (TWIST1-ER; see Table 1)

Table 1. List of various FNE cell lines used in these studies

\begin{tabular}{|c|c|c|c|}
\hline Cell line & Plasmid & Selection marker & Source \\
\hline $\begin{array}{l}\text { FNE-empty (neo) } \\
\text { FNE-m-p553 }\end{array}$ & $\begin{array}{l}\text { pWZL-empty } \\
\text { pWZL-mp53 }\end{array}$ & Neomycin & $\begin{array}{l}\text { Gift from Dr. K. Vousden (Beatson Institute, } \\
\text { Glasgow, UK) }\end{array}$ \\
\hline $\begin{array}{l}\text { FNE-empty (blast) } \\
\text { FNE-m-p53 }\end{array}$ & $\begin{array}{c}\text { pLenti6.3/V5-GFP } \\
\text { pLenti6/V5-p53 } \\
\text { R2495 or R273H }\end{array}$ & Blasticidin & $\begin{array}{c}\text { Addgene (catalog 40125), in-house excision of GFP. } \\
\text { Addgene (catalog 22935; 22934) }\end{array}$ \\
\hline $\begin{array}{l}\text { FNE-empty (neo) } \\
\text { FNE-empty (neo) p53shRNA } 1 \text { or } 2\end{array}$ & $\begin{array}{c}\text { pLKO-empty } \\
\text { pLKO-p53shRNA }{ }^{1} \text { or } 2\end{array}$ & Puromycin & $\begin{array}{c}\text { Dharmacon } \\
\text { Sh1: 5'-ATGTAGTTCTAGTGGATGGTG-3' } \\
\text { Sh2: 5'-TTGCTACAACATGGGCTACAG-3' }\end{array}$ \\
\hline $\begin{array}{l}\text { FNE-m-p53 } 3^{R 175 H} \text { (neo)-empty } \\
\text { FNE-m-p53 }\end{array}$ & $\begin{array}{c}\text { pLKO-empty } \\
\text { pLKO-TWISTshRNA }^{1 \text { or } 2}\end{array}$ & Puromycin & $\begin{array}{c}\text { Dharmacon } \\
\text { Sh1: 5'-AGTCTCCTCGTAAGACTCCGGA-3' } \\
\text { Sh2: 5'-CTTCCCATCTTGGAGTCCAGC-3' }\end{array}$ \\
\hline $\begin{array}{l}\text { FNE-empty (blast)-pLKO } \\
\text { FNE-m-p532R495 or R273H (blast)-pLKO } \\
\text { FNE-empty (blast)-p53shRNA2 }\end{array}$ & $\begin{array}{c}\text { pLKO-empty } \\
\text { pLKO-p53shRNA\#2 }\end{array}$ & Puromycin & $\begin{array}{c}\text { Dharmacon } \\
\text { Sh1: 5'-ATGTAGTTGTAGTGGATGGTG-3' } \\
\text { Sh2: 5'-TTGCTACAACATGGGCTACAG-3' }\end{array}$ \\
\hline
\end{tabular}


A

\section{Control TWIST1-ER}

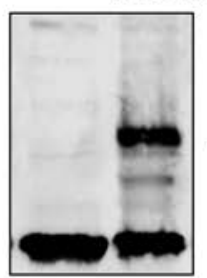

TWIST1 Actin
B

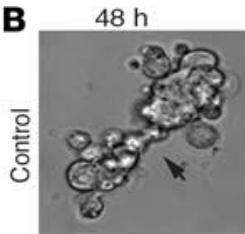
$72 \mathrm{~h}$

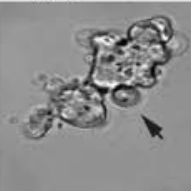
$120 \mathrm{~h}$

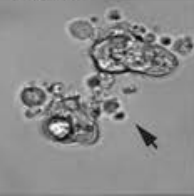

舀

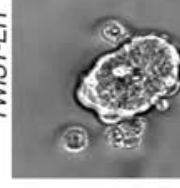

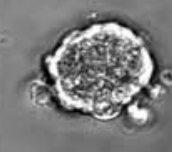

E

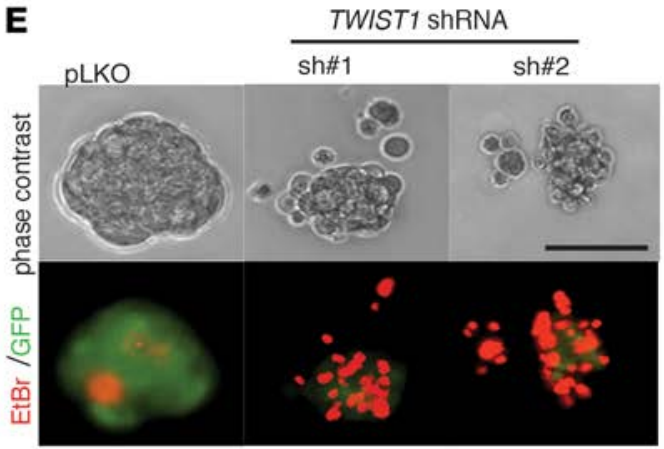

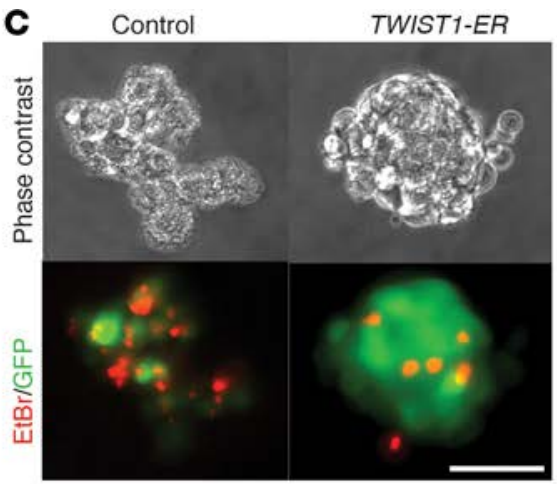

$\mathbf{F}$

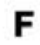

*

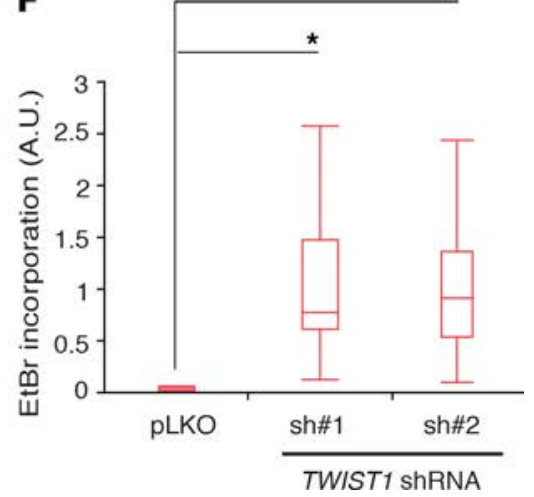

Figure 7. TWIST family BHLH transcription factor 1 (TWIST1) modulates phenotypes associated with mutant p53 (m-p53) expression in fallopian tube nonciliated (FNE) cells. (A) Western blot of lysates of FNE-p53shRNA cells expressing empty vector or TWIST1 fused to the estrogen receptor (TWIST1-ER). (B) Phase-contrast images (Supplemental Video 11) documenting time-dependent (120 hours) disintegration of cellular clusters composed of FNE-p53shRNA cells transduced with control plasmid (empty) or TWIST1-ER and treated with $25 \mathrm{nM} 4$-hydroxytamoxifen 5 days prior to data acquisition. Scale bar: $150 \mu \mathrm{m}$. Eight to ten movies were recorded per condition during 1 acquisition session with 100-150 cells imaged per cluster per movie. (C) Phase-contrast and pseudocolored images of ethidium bromide (EtBr) incorporation into FNE-m-p53 ${ }^{R 175 H}$ cells expressing control plasmid or TWIST1-ER. Scale bar: $100 \mu \mathrm{m}$. (D) Quantification of EtBr incorporation into the various FNE cell lines. $n=35$ (FNE-p53shRNA and control) and $n=55$ (FNE-p53shRNA-TWIST1-ER) clusters scored per condition in 2 separate experiments. (E) Phase-contrast and pseudocolored images of EtBr incorporation into FNE-m-p53 ${ }^{\text {R175H }}$ cells transduced with empty pLKO or TWIST1 shRNAs. Scale bar: $100 \mu \mathrm{m}$. (F) Quantification of EtBr incorporation into the various FNE cell lines. $n=18-20$ clusters scored per condition in 2 separate experiments. All data shown as the median (horizontal bar), interquartile range (box), and minimum/maximum values (whiskers). Statistical analysis performed using 2-tailed Student's $t$ test (D) and 1-way ANOVA and post-hoc Tukey-Kramer test (F). ${ }^{*} P<0.05$ comparing sh\#1 or sh\#2 to pLKO.

in FNE-p53shRNA cells (Figure 7A) caused cell cluster compaction and decreased EtBr incorporation under detached conditions (Figure 7, B-D, and Supplemental Video 11). Conversely, shRNA-mediated knockdown of TWIST1 with two distinct hairpins in FNE-m-p53 ${ }^{\text {R175H }}$ cells (Supplemental Figure 4H) resulted in increased $\mathrm{EtBr}$ incorporation in suspension (Figure 7, E and F). These results indicate that m-p53-dependent inhibition of wild-type p53 and induction of TWIST1 expression promotes survival of FNE cells under conditions of matrix detachment.

Reversion of m-p53 ${ }^{R 175 H}$ conformation with ZMC1 blocks m-p53-induced phenotypes. As a final assessment of the contribution of m-p53 to the phenotypes described in this report, we examined the effects of reversing m-p53 GOF activities using zinc metallochaperone 1 (ZMC1) that restores the wild-type conformation of $\mathrm{m}-\mathrm{p} 53^{\mathrm{R} 175 \mathrm{H}}$ and other m-p53 proteins that are similarly defective in zinc binding (57-60). Treatment of DF30 tumor cells or FNE-m-p53 ${ }^{\mathrm{R} 175 \mathrm{H}}$ cells with $250 \mathrm{nM}$ ZMC1 induced transcription of the wild-type p53 target CDKN1A (Supplemental Figure 5A), indicating that ZMC1 promoted wild-type p53 transcriptional activity of $\mathrm{m}-\mathrm{p} 53^{\mathrm{R} 175 \mathrm{H}}$.

To determine the biological outcome of ZMC1-mediated restoration of m-p53 $3^{\mathrm{R} 175 \mathrm{H}}$ in carcinoma cells, we examined cell-cell adhesion, mesothelial intercalation, and TWIST1 expression after ZMC1 treatment. Treatment of suspended DF30 cells with ZMC1 did not elicit a significant effect on cell viability (as judged by EtBr incorporation) within the first 24 hours of imaging (Supplemental Video 12 and Supplemental Figure 5, B and C), but impaired the ability of these cells to form compacted cell aggregates in short-term (8 hours) assays (Figure 8, A and B, and Supplemental Video 13). In addition, ZMC1 treatment significantly 
A $\quad 0 \mathrm{~h}$

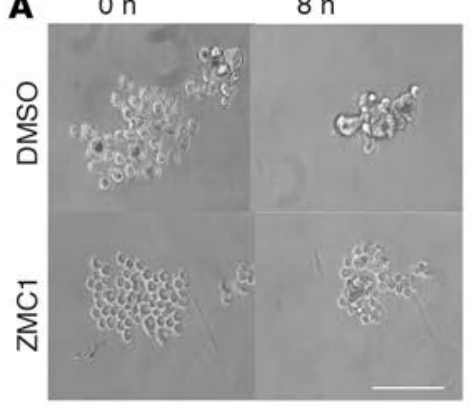

D
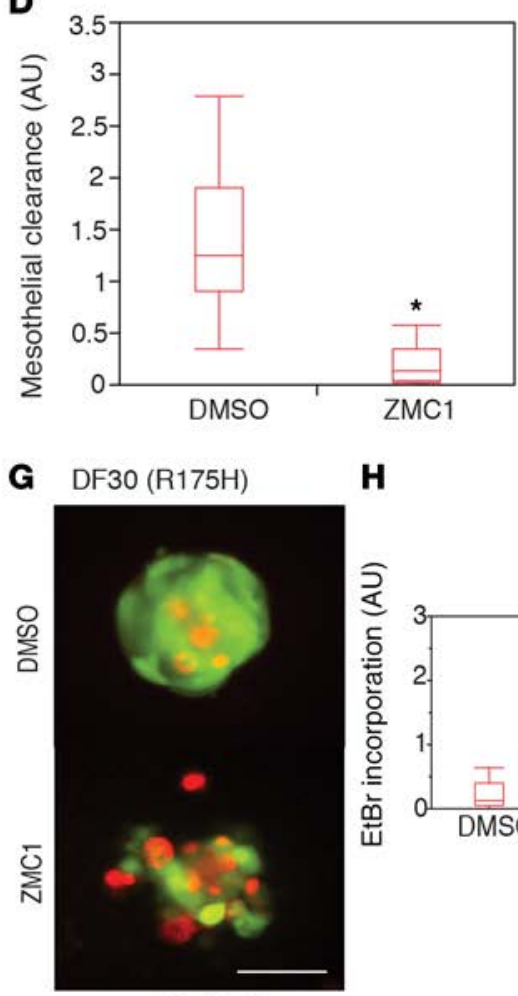

H

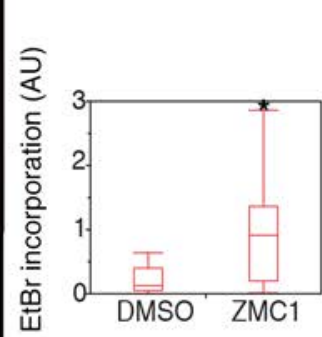

B

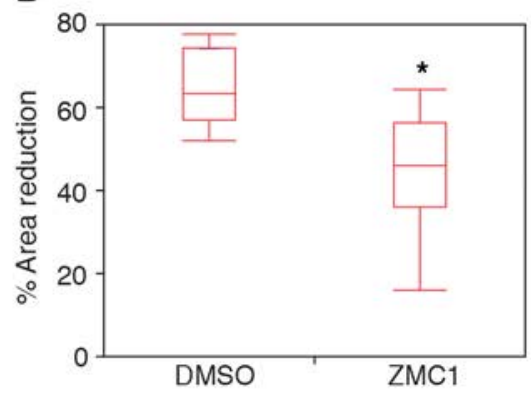

E

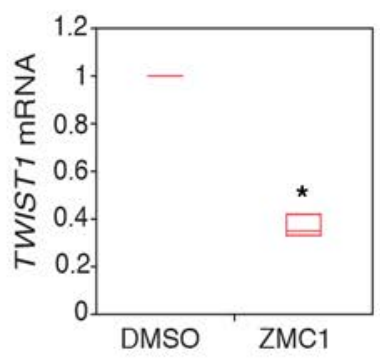

C

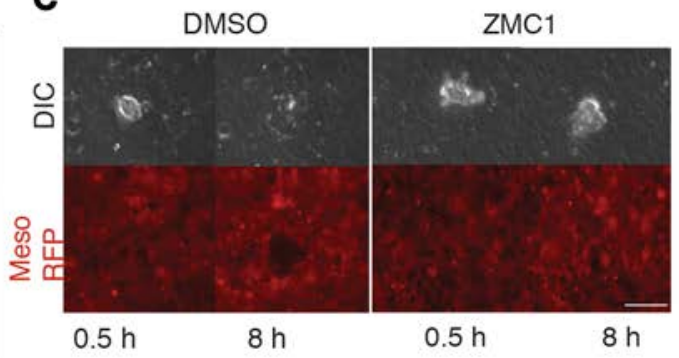

EtBr/GFP

I
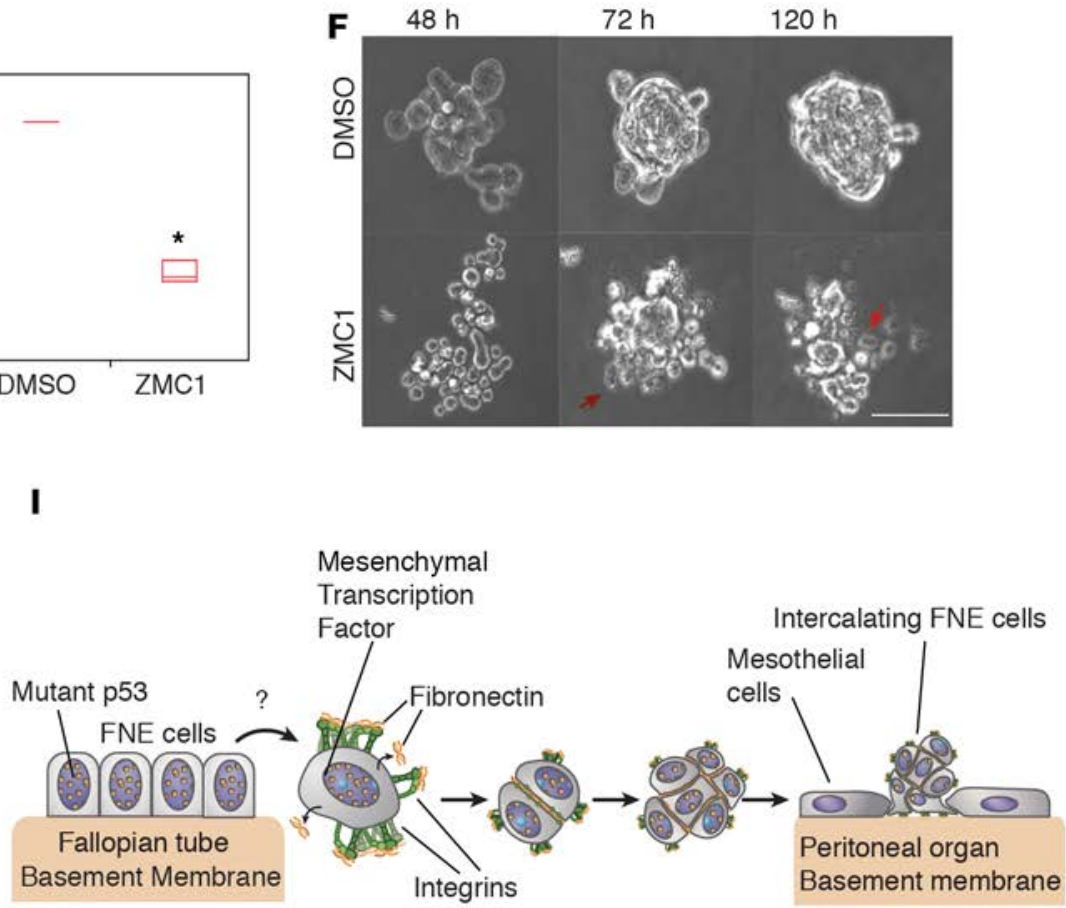

Surviving FNE cells wthout anchorage

to basement membrane

Figure 8. Reversion of mutant $\mathrm{p} 53^{\mathrm{R} 175 \mathrm{H}}$ ( $\mathrm{m}$ - $\mathrm{p5} 3^{\mathrm{R} 175 \mathrm{H}}$ ) conformation with zinc metallochaperone 1 (ZMC1) blocks m-p53 ${ }^{\mathrm{R} 175 \mathrm{H}}$-induced phenotypes. (A) Representative phase-contrast video clips of DF30 cells treated with either DMSO or 250 nM ZMC1 and cultured in suspension for 8 hours (Supplemental Video 13). Representative images from 8 or 9 movies acquired per condition during 1 recording session. Scale bar: $100 \mu \mathrm{m}$. (B) Distribution of the percentage area reduction of DF30 cell clusters from the experiment in panel $\mathbf{A}$. $n=8$ or 9 cell clusters scored per condition. (C) Phase-contrast and pseudocolored (red) images showing the ability of DMSO- or 250 nM ZMC1-treated DF30 cells to clear the mesothelium at the indicated time points (Supplemental Video 14). Scale bar: $150 \mu \mathrm{m}$. (D) Quantification of the mesothelial clearance distribution by DF30 cells treated with DMSO or ZMC1 (250 nM). This experiment was repeated twice with $n=10$ (DMSO) and $n=20$ (ZMC1) cell clusters scored per experiment. (E) TWIST1 mRNA fold change in various fallopian tube nonciliated epithelial (FNE) cells. Values are normalized to FNE control cells. This experiment was performed 3 times with 3 technical replicates. (F) Representative phase-contrast movie clips of DF30 cells treated with either DMSO or $250 \mathrm{nM}$ ZMC1 and cultured in suspension for the indicated time points (Supplemental Video 15). Arrows point to dying cells. (C) Pseudocolored fluorescence images showing ethidium bromide (EtBr) incorporation (red) by DF30 clusters (green) treated with DMSO or $250 \mathrm{nM}$ ZMC1. (H) Distribution of EtBr incorporation by DF30 clusters from 3 independent experiments with $n=44$ (DMSO) and $n=46$ (ZMC1) clusters scored. Each cluster consisted of 100-150 cells. (I) Model of mutant p53-dependent survival of FNE cells that have exfoliated from fimbriae and intercalated into a mesothelial monolayer. All data shown as the median (horizontal bar), interquartile range (box), and minimum/maximum values (whiskers). Statistical analysis performed using 2-tailed Student's $t$ test. ${ }^{*} P<0.05$.

impaired mesothelial clearance (Figure 8, C and D, and Supplemental Video 14) and decreased TWIST1 mRNA expression (Figure 8E). After 72 hours of ZMC1 treatment in suspension, DF30 cell clusters disintegrated and incorporated EtBr (Figure 8, F-H, Supplemental Figure 5, B and C, and Supplemental Videos 12 and 15). Similar results were obtained with FNE-m-p53 ${ }^{\mathrm{R} 175 \mathrm{H}}$ cells (Supplemental Figure 5, D and E). These results indicate that reversion of $\mathrm{m}-\mathrm{p} 53^{\mathrm{R} 175 \mathrm{H}}$ conformation in HGS-OvCa cells blocks the phenotypes 
induced by $\mathrm{m}-\mathrm{p} 53^{\mathrm{R} 175 \mathrm{H}}$ expression described in this report, and provide evidence supporting a constitutive role for zinc-binding-mutant p53 in maintaining these phenotypes.

The effects of ZMC1 treatment suggest that m-p53 expression is required for anchorage-independent survival of DF30 cells. To examine this further, we used p53 shRNAs to attenuate the expression of m-p53 in DF30 cells. p53 shRNAs caused a decrease in both fibronectin and integrin $\alpha 5$ protein expression (Supplemental Figure 6A) and in the ability to form compacted spheroids, and induced EtBr incorporation, which correlated with the degree of m-p53 knockdown, when compared to control cells expressing nontargeting shRNA (Supplemental Figure 6, B and C, and Supplemental Video 16). These results provide evidence that stabilized m-p53 is required for anchorage-independent survival of HGS-OvCa cells.

\section{Discussion}

These studies provide potentially new insights into the mechanisms whereby FT epithelial cells that represent the cells-of-origin of $\mathrm{HGS}-\mathrm{OvCa}$ acquire phenotypes associated with ovarian cancer dissemination from the fimbriae $(1,5,22,61-64)$. The combined use of human FNE cultures and live-cell microscopybased assays that assess phenotypes associated with early stages of ovarian cancer dissemination made it possible to examine in real time and space the activity of m-p53 in the cells-of-origin of most HGS-OvCa. The data presented here are consistent with a model in which FT epithelial cells acquire transformed phenotypes through m-p53-dependent regulation of mesenchymal TFs and autocrine deposition of matrix in the absence of basement membrane attachment (Figure 8I).

The utilization of long-term live-cell imaging revealed that FNE cells expressing m-p53 are able to survive and form multicellular clusters in suspension, a phenotype that is predicted to be essential for transit of exfoliated FT cells through the peritoneal fluids. Our experiments also revealed that these multicellular clusters have the ability to intercalate into cultured mesothelial monolayers, which resemble the mesothelial lining of peritoneal tissues, the most common site of HGS-OvCa dissemination.

The majority of human ovarian carcinoma cells isolated from peritoneal washes exhibit a high degree of cell aggregation, and it has been postulated that their survival in the suspended environment of the peritoneal cavity depends on their ability to adhere to each other and form cell clusters (65). In this study, we found that m-p53 promoted FNE cell-cell adhesion in suspension, but this adhesion was not required for survival of detached cells.

We previously reported that the ability of ovarian cancer cell clusters to intercalate into a mesothelial monolayer was dependent on integrin $\alpha 5 \beta 1$ (21). Here, we demonstrated that the function of $\alpha 5 \beta 1$ was required for m-p53-dependent survival of FNE cells cultured in suspension, raising the possibility that m-p53 promotes anchorage-independent survival through the deposition of fibronectin, the ligand for $\alpha 5 \beta 1$. Indeed, we found that m-p53 promoted production and deposition of fibronectin in FNE cells cultured in suspension, leading to the formation of de novo matrix adhesions that contribute to anchorageindependent survival. The presence of fibronectin and activated integrin $\beta 1$ in patient-derived tumor cell aggregates from ascites raises the possibility that disseminating FT secretory cells that express GOF p53 mutants are not anchorage deprived because they produce their own matrix. In addition, other studies have implicated increased matrix production in early FT cancers (66) and integrin-mediated signaling in sustaining survival of HGS-OvCa cells under detachment conditions $(67,68)$. m-p53-dependent formation and maintenance of integrin adhesion under detachment conditions provides a distinctive mechanism of avoiding anoikis. This mechanism is likely to involve self-activation (through autocrine matrix deposition) of integrin $\alpha 5 \beta 1$ proximal signals that stimulate prosurvival and antiapoptotic pathways. It is of therapeutic interest to understand the nature of these pathways and develop specific inhibitors to target matrix dependencies in cells that have exfoliated into the peritoneal space.

Epithelial-to-mesenchymal transition (EMT) is a transcriptional program that has been reported to be associated with metastatic activity in several tumor types (69). Increased fibronectin or TWIST1 expression is often associated with EMT $(70,71)$. Studies of other cancer types have shown that single tumor cells circulating in patients' blood express a mesenchymal program characterized by induction of fibronectin and mesenchymal TF gene expression (72-74). In addition, we previously reported that a significant portion ( $~ 50 \%$ of samples analyzed) of patient-derived HGS-OvCa cell clusters isolated from ascites express mesenchymal markers (22), among which TWIST1 was required to support ovarian cancer intercalation into mesothelial cell layers. Consistent with these results, in this report, we found that m-p53, but not shRNAmediated knockdown of wild-type p53, induced the expression of TWIST1. Ectopic expression of TWIST1 
in the background of endogenous p53 depletion promoted survival of FNE cells in suspension, indicating that both the loss of wild-type p53 function and the gain of mesenchymal transcription contribute to the transformed phenotypes induced by m-p53. While TWIST1 was induced in FNE-m-p53 ${ }^{\text {R175H }}$ cells, DF30, and other mesenchymal-like tumor cell lines, it is likely that other mesenchymal TFs induced by different mutant variants of p53 are involved in regulating mesenchymal phenotypes associated with HGS-OvCa.

p53 $3^{\mathrm{R} 175 \mathrm{H}}$ has been shown to induce TWIST1 expression through BMI-1 (also known as polycomb RING finger) repression and a subsequent decrease in histone $\mathrm{H} 3$ methylation upstream of the TWIST1 promoter (48), suggesting that the induction of mesenchymal transition by m-p53 involves regulation of chromatin. Studies by Zhu et al. (45) demonstrated that GOF activity of m-p53 involves its direct binding to promoters of chromatin regulatory genes and subsequent induction of methyl- and acetyltransferase expression. These studies raise the possibility that the m-p53-induced phenotypes we describe in this study may be dependent on regulation of chromatin and subsequent expression of genes that support FNE cell survival and mesothelial intercalation. It is also possible that m-p53-dependent inhibition of other p53 family members (e.g., p63) is involved in the mesenchymal transition (75-77) and integrin $\alpha 5 \beta 1$ dependencies (78) observed in FT cells. There is a lack of evidence for p63 expression in the FT secretory cells, and reports of p63 expression in HGS-OvCa vary significantly (79); thus, a careful assessment of p63 protein expression in human tumors is warranted as well as an evaluation of its involvement in mesenchymal transitions.

In this report, we provide evidence that anchorage-independent survival of HGS-OvCa cells depends on m-p53 function. Attenuation of m-p53 expression in HGS-OvCa cells promoted loss of anchorage independence, suggesting that constitutive expression of m-p53 is required for survival of cells that disseminate into the peritoneum. In addition, in short-term assays, restoration of the m-p53 conformation with ZMC1 decreased FNE cell-cell adhesion and TWIST1 expression, indicating that GOF activity of m-p53 is required to maintain the phenotypes described here. Findings from other laboratories have provided evidence that restoration of wild-type p53 function suppresses tumor growth. In a murine model, restoration of wild-type p53 expression in tumors carrying a missense TP53 mutation has been shown to halt tumor growth (80). More recent studies by Soragni et al. (81) demonstrated that rescue of p53 tumor suppression, using a peptide that disrupts aggregation of accumulated and misfolded m-p53 molecules, induced ovarian cancer cell death. The development and evaluation of specific and nontoxic small-molecule p53 reactivators that target the $\mathrm{m}$-p 53 protein will be required to test whether interfering with $\mathrm{m}$-p 53 -dependent pathways is of clinical importance.

m-p53-immunopositive early lesions within fimbriae (p53 signature) are benign and nonproliferative $(3,7)$. These observations suggest that additional genetic alterations are required for $\mathrm{m}$-p 53 -positive secretory cells to acquire these properties. It is possible that changes in the microenvironment influence some of the m-p53 phenotypes observed in this report; e.g., dissociation from the tissue environment and growth in suspension could provide a more permissive environment for expression of the mesenchymal phenotype. We have observed that $\sim 50 \%$ of ascites samples express vimentin, whereas only a small percentage of solid HGS-OvCa are vimentin positive (22). This supports the idea that FT epithelial cells harboring GOF TP53 mutations acquire a mesenchymal phenotype during transit through the fluidic environment of the peritoneum and, following intercalation into peritoneal organs, lose this phenotype.

In summary, we have developed culture techniques and live-cell microscopy-based assays to examine the activities of m-p53 in the cell-of-origin of HGS-OvCa. Our studies have provided important insights into the molecular programs regulated by m-p53 during the early stages of HGS-OvCa progression and suggest that m-p53 provides a selective advantage by allowing FT epithelial cells to cope with the cellular stress that is associated with crossover of altered secretory cells from the FT to the mesothelium-covered ovary or other peritoneal organs during HGS-OvCa dissemination.

\section{Methods}

Cell culture. FNE cells were isolated and adopted to culture conditions as described previously (26), and maintained in WIT-Fo Culture Media (FOMI, http://sylvester.org/shared-resources/live-tumor-culturecore/live-tumor-culture-core-products) supplemented with EGF (0.01 $\mu \mathrm{g} / \mathrm{ml}$; Sigma-Aldrich); insulin (20 $\mu \mathrm{g} / \mathrm{ml}$; Sigma-Aldrich); hydrocortisone $(0.5 \mu \mathrm{g} / \mathrm{ml})$; cholera toxin $(25 \mathrm{ng} / \mathrm{ml}$; Calbiochem $)$, and $1 \%$ heatinactivated FBS (Sigma-Aldrich). Under an IRB approval and with informed consent, primary HGS-OvCa cells (DF30) were isolated as previously described (22). All DF cells were cultured in OCMI-L media 
(purchased from the Live Tumor Culture Core, University of Miami) supplemented with $25 \mathrm{ng} / \mathrm{ml}$ of cholera toxin. HEK293T cells were cultured in DMEM (Gibco) containing 10\% serum and 1\% penicillinstreptomycin. All cells were cultured in $5 \% \mathrm{CO}_{2}$ at $37^{\circ} \mathrm{C}$. Ovarian cancer cell lines were cultured in a 1:1 mixture of MCDB105 (Sigma-Aldrich) and M199 (Gibco) media supplemented with 5\% FBS.

Live cell cluster disintegration assay. FNE or DF30 cells were seeded in low-adhesion 96-well round bottom plates (Corning). Cells were briefly spun at $127 \mathrm{~g}$ for 3 minutes. To generate cellular clusters, cells were returned to the incubator for 24 to 48 hours. Cellular clusters were then imaged for 48 hours at 20 - to 30-minute intervals using a Nikon Ti-E inverted motorized widefield fluorescence microscope with integrated Perfect Focus System and (20×, 0.45 NA) magnification/NA phase/DIC optics equipped with a $\mathrm{CO}_{2}$ - and temperature-controlled incubation chamber. The resulting movies were compressed and stitched using Quick Time Pro and Adobe After Effects software.

EtBr incorporation assay. FNE cells expressing GFP were seeded in low-adhesion 96-well round bottom plates (Corning) at a density of 100-150 cells per well. Cells were briefly spun at $127 \mathrm{~g}$ for 3 minutes and allowed to form cellular clusters for 24, 48, or 120 hours depending on the experiment. At the end of each time period, cellular clusters were treated with $2 \mu \mathrm{M}$ EtBr (Molecular Probes). To follow EtBr incorporation into live structures, EtBr was included in the medium during cell seeding. Phase-contrast and/or fluorescent images of cellular clusters were acquired every 20-30 minutes using the Nikon Ti-E microscope described above and low (10×, $0.30 \mathrm{NA})$ magnification/NA phase optics, Nikon halogen trans illuminator with 0.52 NA LWD condenser, Nikon fast ( $<100 \mathrm{~ms}$ switching time) excitation and emission filter wheels, Sutter fast transmitted and epifluorescence light path Smart Shutters, Nikon linear-encoded motorized stage, Hamamatsu ORCA-AG cooled CCD camera, custom-built microscope incubation chamber with temperature and $\mathrm{CO}_{2}$ control, Nikon NIS Elements AR software v4, and a TMC vibration-isolation table. The level of EtBr incorporation into GFP-labeled cellular structures was quantified by using 2 independent methods. One method involved subtracting channel-specific autofluorescent signal from the mean gray value pixel intensity of each channel (red and green). The resulting mean gray value pixel intensity of the red signal was divided by the mean gray value pixel intensity of the green signal for each individual cell cluster. The average value of the red-to-green ratio was obtained from examined cell clusters. Individual value ratios (red/green) were further divided by the mean of the group that showed greater EtBr incorporation. The second method of measuring EtBr incorporation into cellular clusters relied on measuring changes in the total number of pixels (red channel) present within cellular clusters over time.

Live cell-cell aggregation/spheroid formation assay. FNE cells were seeded in low-adhesion plates as described above and imaged for 24 hours at 10- to 15-minute intervals using the Nikon Ti-E microscope. To quantify percentage area reduction, the final area of cell cluster occupancy (24-hour time frame) was divided by the initial area of cell cluster occupancy (0-hour time frame). The resulting number was subtracted from 1 and multiplied by 100 .

Live single-cell assay. To prepare the single-cell culture polydimethylsiloxane (PDMS) microwells, we followed a previously published protocol (82). Briefly, Sylgard 184 silicone elastomer base and curing agent were mixed at a 10:1 ratio. The solution was degassed and poured over a micropatterned SU- 8 wafer with $100-\mu \mathrm{m}^{2}$ microwells. These devices were placed in an oven at $80^{\circ} \mathrm{C}$ for 1.5 hours. Four- to six-millimeter-thick PDMS devices were detached from the wafer and were bonded using a plasma etcher (Harrick Plasma) to the glass bottom surface of a 12-well plate (MatTek). Cells were plated at a density of 500 cells per well onto PDMS multimicrowell culture devices, allowed to settle in the incubator for 60 minutes, and were then filmed for 72 hours in the presence or absence of $2 \mu \mathrm{M} \mathrm{EtBr}$ using the Nikon Ti-E microscope described above and low (20×, $0.45 \mathrm{NA})$ magnification/NA phase optics equipped with a $\mathrm{CO}_{2}$ - and temperature-controlled incubation chamber. Only wells occupied by single cells were used for quantification.

Mesothelial clearance assay. The mesothelial cells were plated on glass-bottom dishes (Mat-TEK) coated with $5 \mu \mathrm{g} / \mathrm{ml}$ of fibronectin (Sigma-Aldrich) and/or collagen I (Sigma-Aldrich). Cells were maintained in culture until confluent (48 hours after plating). To generate cell clusters, FNE cells were dissociated by trypsinization, washed twice with PBS, resuspended in culture medium, and plated on poly(2-hydroxyethyl methacrylate)-coated culture dishes. Cell clusters were collected for experiments 36-48 hours later and consisted of 100 to 500 cells per cluster. In coculture experiments, cell clusters were added to a confluent mesothelial monolayer expressing red fluorescent protein (RFP), allowed to attach for 30 to 60 minutes, and imaged for 8 hours using the Nikon Ti-E microscope. Only cellular clusters that remained attached during the experiment were used for quantification. Mesothelial clearance was quantified as previously described (21). 
Generation of FNE cell lines. Table 1 lists the various FNE cell lines that were generated for this study.

Transfection of FN1 siRNA oligonucleotides. We used the Dharmacon protocol for transfecting siRNA oligonucleotides into FNE cells (http://dharmacon.gelifesciences.com/uploadedFiles/Resources/ basic-dharmafect-protocol.pdf). The following Dharmacon FN1 siRNAs were used: siRNA\#2 (catalog J-009853-07; 5'-GAAUAGAUGCAACGAUCA-3') and siRNA\#4 (catalog J-009853-09; 5'-CCUAAAGACUCCAUGAUCU-3').

Lentivirus and retrovirus production and infection of FNE cells. To generate lentiviral particles, HEK293FT cells (Invitrogen) were transduced with packaging plasmids pLP1, pLP2, and VSVG (Invitrogen), and the plasmid containing the gene of interest. Culture supernatants were collected 48 and 72 hours after transduction. FNE cells were infected and selected with appropriate antibiotics 48 hours after infection. To generate retroviral particles, HEK293FT (ATCC) cells were transduced with packaging plasmid pCL-Ampho and plasmid containing the gene of interest. Culture supernatants were collected 72 and 96 hours after transduction. FNE cells were infected and selected as described above.

ZMC1-dependent m-p53 reactivation. ZMC-1 was a generous gift from Darren Carpizo (Rutgers University, New Brunswick, New Jersey, USA). FNE-mp53 ${ }^{\mathrm{R} 175 \mathrm{H}}$ or DF30 cells were seeded in 6-well plates at a density of 50,000 cells per well, allowed to grow for 24 hours, and then treated with $250 \mathrm{nM} \mathrm{ZMC1}$ or vehicle control (DMSO) for another 24 hours. Following treatment, cells were detached and monitored in suspension for 24 to 120 additional hours in the presence of $\mathrm{ZMC1}$ at the indicated concentration.

Blocking antibody experiments. The following function-blocking antibodies were used: anti-N-cadherin (Sigma-Aldrich; catalog C3865) used at $4 \mu \mathrm{g} / \mathrm{ml}$; anti-MUC16 (a generous gift from David Spriggs, Memorial Sloan Kettering Cancer Center, New York, New York, USA) used at $4 \mu \mathrm{g} / \mathrm{ml}$; and anti-integrin $\beta 1$ (AIIB2) and anti-integrin $\alpha 5$ (P1D6) were purchased from the Hybridoma Bank at the University of Iowa (Iowa City, Iowa, USA) and used at $2.8 \mu \mathrm{g} / \mathrm{ml}, 1.4 \mu \mathrm{g} / \mathrm{ml}$, and $0.7 \mu \mathrm{g} / \mathrm{ml}$. AIIB2 and P1D6 were deposited by Caroline H. Damsky (University of California, San Francisco, California, USA) and Elizabeth Wayner (Fred Hutchinson Cancer Research Center, Seattle, Washington, USA), respectively. To perform functionblocking experiments, FNE-mp53 ${ }^{\mathrm{R} 175 \mathrm{H}}$ or DF30 cells were incubated for the indicated period of time at a density of $100-150$ cells per single low-adhesion well containing $150 \mu$ of FOMI media and supplemented with various function-blocking antibodies at the indicated concentration. The cellular clusters were either filmed for the indicated period of time in the presence or absence of EtBr or stained with EtBr after filming.

Immunofluorescence. Cellular clusters were spun at $127 \mathrm{~g}$ for 3 minutes in 96-well glass-bottom plates coated with poly-D-lysine (Sigma-Aldrich), gently washed with PBS, and fixed in $2 \%$ paraformaldehyde for 15 minutes. Following fixation, cellular clusters were incubated for 30 minutes in antibody blocking buffer containing 20\% goat serum and 5\% BSA (Sigma-Aldrich), and stained overnight at $4^{\circ} \mathrm{C}$ with antibodies against: human fibronectin (Sigma-Aldrich; catalog F3648); human active integrin $\beta 1$ (9EG7; BD Pharmingen; catalog 550531), MUC16 (generous gift from David Spriggs), and N-cadherin (SigmaAldrich), all diluted in blocking buffer. Cellular clusters were washed 3 times with PBS and stained with secondary antibody reagent for 60 minutes at room temperature (Molecular Probes). Cellular clusters were washed 3 times with PBS, leaving $150 \mu 1$ of PBS in each well. Antigen-antibody complexes were detected using a Nikon A1 confocal microscope.

Protein precipitation from serum-free culture media. Cells were cultured in serum-free media for 24 hours, at which point the media were collected and the cells processed for total loading-controlled (actin) Western blot analysis (see below). Proteins were precipitated from the media by adding $1 / 4$ volume of ice-cold trichloroacetic acid and incubated on ice for 25 minutes. Samples were spun at 18,000 $\mathrm{g}$ for 20 minutes. Protein pellets were washed twice with ice-cold acetone and spun at 18,000 $g$ for 5 minutes after each wash. Pellets were air-dried and resuspended in SDS sample buffer.

Western blot analysis (full, uncut gel(s) available in Supplemental Figure 7). Cells were lysed in RIPA buffer (50 mM HEPES pH 7.4, 1\% Triton X-100, 1\% sodium deoxycholate, $0.1 \%$ SDS, $0.1 \mathrm{M} \mathrm{NaCl}, 1 \mathrm{mM}$ sodium orthovanadate, $0.1 \mathrm{M}$ sodium pyrophosphate, $100 \mathrm{mM} \mathrm{NaF}, 1 \mathrm{mM}$ PMSF, and $1 \mu \mathrm{M}$ MG-132 [Selleck Chemicals; catalog S.2619]). Lysates were clarified by centrifugation at $13,000 \mathrm{~g}$ for 10 minutes at $4^{\circ} \mathrm{C}$, protein concentration was quantified using the BCA assay (Pierce), and absorbance was read on an Epoch MicroVolume Spectrophotometer System (BioTEK). Lysates were boiled in sample buffer $(0.04 \mathrm{M}$ Tris- $\mathrm{HCl} \mathrm{pH} 6.8$, $1 \%$ SDS, $1 \% \beta$-mercaptoethanol, and 10\% glycerol) for 10 minutes and resolved by SDS-PAGE. Proteins were transferred to Immobilon membranes (Whatman) and blocked with $5 \% \mathrm{BSA}$ in PBS (140 mM NaCl, 0.27 $\mathrm{mM} \mathrm{KCl}, 0.43 \mathrm{mM} \mathrm{Na}_{2} \mathrm{HPO}_{4}, 0.14 \mathrm{mM} \mathrm{KH}_{2} \mathrm{PO}_{4}, \mathrm{pH}$ 7.3) for 30 minutes at room temperature. Membranes 
were incubated overnight at $4^{\circ} \mathrm{C}$ with one or more of the following Abs: E-cadherin monoclonal $\mathrm{Ab}(1: 1,000$; Becton Dickinson; catalog 610182); fibronectin monoclonal Ab (1:1,000; Millipore; catalog MAB1937); actin monoclonal Ab (1:20,000; Sigma-Aldrich; catalog A1978); laminin $\lambda 1$ polyclonal Ab (1:1,000; SigmaAldrich; catalog HA001908); integrin $\alpha 5$ polyclonal Ab (1:1,000; Cell Signaling Technology; catalog 4705); TWIST1 polyclonal Ab (1:500; Santa Cruz Biotechnology; catalog sc-81417), p53 monoclonal Ab (1:1,000; Cell Signaling Technology; catalog 2527); and p53 monoclonal Ab (1:1,000; Santa Cruz Biotechnology; catalog sc-126). Membranes were then probed with secondary antibodies linked to either HRP (1:5,000; Santa Cruz Biotechnology; catalog sc-2031, 2030) or to fluorophores (1:15,000; LI-COR Biosciences; catalog 92632280 and 926-68071). Membranes were developed using an enhanced chemiluminescent substrate (VWR) and visualized using a Kodak film developer and an Epson 3000 scanner (for HRP) or visualized using the Odyssey Imaging System (LI-COR Biosciences) (for fluorophores).

Quantitative RT-PCR. RNA was isolated with an RNeasy Micro Kit (QIAGEN) and reverse transcribed into cDNA using the qScript cDNA Synthesis Kit (Quanta) according to the manufacturers' instructions. cDNA levels were quantified by the SYBR green method on a 7900HT Fast Real-Time PCR system (Life Technologies) in a 384-well format. Triplicate samples were quantified along with minus-RT and minustemplate controls. Amplification was continued for 40 cycles as follows: $94^{\circ} \mathrm{C}$ for 10 seconds, $55^{\circ} \mathrm{C}$ for 15 seconds, and $65^{\circ} \mathrm{C}$ for 30 seconds. Relative gene expression among the various FNE cells was determined by normalizing to the PRLPO endogenous control, and the resulting value was divided by the central median value of the particular gene across all analyzed samples in the experiment. The following PCR probes were used in these studies: CDKN1A Forward, 5'-TCACTGTCTTGTACCCTTGTGC-3'; Reverse, 5'-GGCGTTTGGAGTGGTAGAAA-3'; TWIST1 Forward, 5'-AGCTACGCGTTCTCGGTC-3'; Reverse, 5'-GGCGTTTGGAGTGGTAGAAA-3'; SNAI1 (SNAIL) Forward, 5'-CCTCCCTGTCAGATGAGGAC-3'; Reverse, 5'-CCAGGCTGAGGTATTCCTTG-3'; SNAI2 (SLUG) Forward, 5'-TGGTTGCTTCAAGGACACAT-3'; Reverse, 5'-GCAATGCTCTGTTGCAGTG-3'.

Statistics. Box and whisker plots were generated using JMP.PRO 9.0.0 software (SAS Institute) and Prism 6.0. Box plots represent distribution of individual data points with the median (horizontal line within the box), interquartile range (box), and minimum/maximum values (whiskers). Line graphs were generated using PRISM6 software. Statistical significance in the experiments involving comparison of 2 groups was calculated by 2-tailed Student's $t$ test, where normal distribution of data points is assumed. We employed a 1-way ANOVA and/or Tukey-Kramer test to calculate statistical significance in the experiments involving more than 2 groups. A $P$ value less than 0.05 was considered significant ( $95 \%$ confidence).

\section{Author contributions}

MI, TI, RD, and JB conceived the experimental plan, interpreted the data, and drafted the manuscript. MI designed and developed the microscopy assays. TI isolated and adapted the culture conditions for FNE cells. RD contributed patient material and immunohistochemical data. MI and HYC generated additional FNE cell lines. IZ designed the single-cell culture devices. CI, TM, and MN helped with Western blotting, immunostaining, and qPCR. All authors reviewed the manuscript.

\section{Acknowledgments}

We would like to thank M. Angelica Martinez-Gakidis for help with editing of the manuscript and helpful discussions, Jennifer Waters and the Nikon Imaging Center at Harvard Medical School for support on the microscopy studies, and all the Brugge lab members for study support. We also thank Grace Gao for lab management. These studies were supported by the Dr. Miriam and Sheldon G. Adelson Medical Research Foundation (JB and RD) and NIH P50-CA083636 (RD).

Address correspondence to: Joan S. Brugge, Department of Cell Biology, 240 Longwood Avenue, Boston, Massachusetts 02115, USA. Phone: 617.432.3974; E-mail: Joan_Brugge@hms.harvard.edu. Or to: Ronny Drapkin, Penn Ovarian Cancer Research Center, Basser Center for BRCA, 421 Curie Boulevard, Perelman School of Medicine, University of Pennsylvania, Philadelphia, Pennsylvania 19104, USA. Phone: 215.746.3973; E-mail: rdrapkin@mail.med.upenn.edu.

Marián Novak’s present address is: Personal Genome Diagnostics, Baltimore, Maryland, USA. 
1. Cannistra SA. Cancer of the ovary. NEngl J Med. 2004;351(24):2519-2529.

2. Cannistra SA. Cancer of the ovary. N Engl J Med. 1993;329(21):1550-1559.

3. Levanon K, Crum C, Drapkin R. New insights into the pathogenesis of serous ovarian cancer and its clinical impact. J Clin Oncol. 2008;26(32):5284-5293.

4. Bowtell DD, et al. Rethinking ovarian cancer II: reducing mortality from high-grade serous ovarian cancer. Nat Rev Cancer. 2015;15(11):668-679.

5. Vaughan S, et al. Rethinking ovarian cancer: recommendations for improving outcomes. Nat Rev Cancer. 2011;11(10):719-725.

6. Crum CP, et al. The distal fallopian tube: a new model for pelvic serous carcinogenesis. Curr Opin Obstet Gynecol. 2007;19(1):3-9.

7. Lee Y, et al. A candidate precursor to serous carcinoma that originates in the distal fallopian tube. J Pathol. 2007;211(1):26-35.

8. Medeiros F, et al. The tubal fimbria is a preferred site for early adenocarcinoma in women with familial ovarian cancer syndrome. Am J Surg Pathol. 2006;30(2):230-236.

9. Berns EM, Bowtell DD. The changing view of high-grade serous ovarian cancer. Cancer Res. 2012;72(11):2701-2704.

10. Ahmed AA, et al. Driver mutations in TP53 are ubiquitous in high grade serous carcinoma of the ovary. $J$ Pathol. 2010;221(1):49-56.

11. Tothill RW, et al. Novel molecular subtypes of serous and endometrioid ovarian cancer linked to clinical outcome. Clin Cancer Res. 2008;14(16):5198-5208.

12. Cancer Genome Atlas Research Network. Integrated genomic analyses of ovarian carcinoma. Nature. 2011;474(7353):609-615.

13. Vang R, Levine DA, Soslow RA, Zaloudek C, Shih IeM, Kurman RJ. Molecular alterations of TP53 are a defining feature of ovarian high-grade serous carcinoma: a rereview of cases lacking TP53 mutations in The Cancer Genome Atlas Ovarian study. Int J Gynecol Pathol. 2016;35(1):48-55.

14. Cai Q, Yan L, Xu Y. Anoikis resistance is a critical feature of highly aggressive ovarian cancer cells. Oncogene. 2015;34(25):3315-3324

15. Brown CW, Brodsky AS, Freiman RN. Notch3 overexpression promotes anoikis resistance in epithelial ovarian cancer via upregulation of COL4A2. Mol Cancer Res. 2015;13(1):78-85.

16. Carduner L, Picot CR, Leroy-Dudal J, Blay L, Kellouche S, Carreiras F. Cell cycle arrest or survival signaling through $\alpha v$ integrins, activation of PKC and ERK1/2 lead to anoikis resistance of ovarian cancer spheroids. Exp Cell Res. 2014;320(2):329-342.

17. Mitra AK, Sawada K, Tiwari P, Mui K, Gwin K, Lengyel E. Ligand-independent activation of c-Met by fibronectin and $\alpha(5)$ $\beta(1)$-integrin regulates ovarian cancer invasion and metastasis. Oncogene. 2011;30(13):1566-1576.

18. Kenny HA, Nieman KM, Mitra AK, Lengyel E. The first line of intra-abdominal metastatic attack: breaching the mesothelial cell layer. Cancer Discov. 2011;1(2):100-102.

19. Lengyel E, et al. Epithelial ovarian cancer experimental models. Oncogene. 2014;33(28):3619-3633.

20. Kenny HA, Krausz T, Yamada SD, Lengyel E. Use of a novel 3D culture model to elucidate the role of mesothelial cells, fibroblasts and extra-cellular matrices on adhesion and invasion of ovarian cancer cells to the omentum. Int J Cancer. 2007;121(7):1463-1472.

21. Iwanicki MP, et al. Ovarian cancer spheroids use myosin-generated force to clear the mesothelium. Cancer Discov. 2011;1(2):144-157.

22. Davidowitz RA, et al. Mesenchymal gene program-expressing ovarian cancer spheroids exhibit enhanced mesothelial clearance. J Clin Invest. 2014;124(6):2611-2625.

23. Ahmed AA, Becker CM, Bast RC Jr. The origin of ovarian cancer. BJOG. 2012;119(2):134-136.

24. Piek JM, et al. Dysplastic changes in prophylactically removed Fallopian tubes of women predisposed to developing ovarian cancer. J Pathol. 2001;195(4):451-456.

25. Laury AR, et al. Fallopian tube correlates of ovarian serous borderline tumors. Am J Surg Pathol. 2011;35(12):1759-1765.

26. Merritt MA, et al. Gene expression signature of normal cell-of-origin predicts ovarian tumor outcomes. PLoS ONE. 2013;8(11):e80314.

27. Przybycin CG, Kurman RJ, Ronnett BM, Shih IeM, Vang R. Are all pelvic (nonuterine) serous carcinomas of tubal origin? Am J Surg Pathol. 2010;34(10):1407-1416.

28. Perets R, Drapkin R. It's totally tubular...riding the new wave of ovarian cancer research. Cancer Res. 2016;76(1):10-17.

29. Leeper K, Garcia R, Swisher E, Goff B, Greer B, Paley P. Pathologic findings in prophylactic oophorectomy specimens in highrisk women. Gynecol Oncol. 2002;87(1):52-56.

30. Kindelberger DW, et al. Intraepithelial carcinoma of the fimbria and pelvic serous carcinoma: evidence for a causal relationship. Am J Surg Pathol. 2007;31(2):161-169.

31. Carlson JW, et al. Serous tubal intraepithelial carcinoma: its potential role in primary peritoneal serous carcinoma and serous cancer prevention. J Clin Oncol. 2008;26(25):4160-4165

32. Gross AL, Kurman RJ, Vang R, Shih IeM, Visvanathan K. Precursor lesions of high-grade serous ovarian carcinoma: morphological and molecular characteristics. J Oncol. 2010;2010:126295.

33. Marquez RT, et al. Patterns of gene expression in different histotypes of epithelial ovarian cancer correlate with those in normal fallopian tube, endometrium, and colon. Clin Cancer Res. 2005;11(17):6116-6126.

34. Shaw PA, Rouzbahman M, Pizer ES, Pintilie M, Begley H. Candidate serous cancer precursors in fallopian tube epithelium of BRCA1/2 mutation carriers. Mod Pathol. 2009;22(9):1133-1138.

35. Perets R, et al. Transformation of the fallopian tube secretory epithelium leads to high-grade serous ovarian cancer in Brca;Tp53;Pten models. Cancer Cell. 2013;24(6):751-765.

36. Kim J, Coffey DM, Creighton CJ, Yu Z, Hawkins SM, Matzuk MM. High-grade serous ovarian cancer arises from fallopian tube in a mouse model. Proc Natl Acad Sci USA. 2012;109(10):3921-3926.

37. Sherman-Baust CA, et al. A genetically engineered ovarian cancer mouse model based on fallopian tube transformation mimics human high-grade serous carcinoma development. J Pathol. 2014;233(3):228-237.

38. Karst AM, Drapkin R. Primary culture and immortalization of human fallopian tube secretory epithelial cells. Nat Protoc. 2012;7(9):1755-1764.

39. Karst AM, Levanon K, Drapkin R. Modeling high-grade serous ovarian carcinogenesis from the fallopian tube. Proc Natl Acad 
Sci USA. 2011;108(18):7547-7552.

40. Jazaeri AA, et al. Molecular requirements for transformation of fallopian tube epithelial cells into serous carcinoma. Neoplasia. 2011;13(10):899-911.

41. Boylan KL, et al. Claudin 4 Is differentially expressed between ovarian cancer subtypes and plays a role in spheroid formation. Int J Mol Sci. 2011;12(2):1334-1358.

42. Casey RC, et al. Beta 1-integrins regulate the formation and adhesion of ovarian carcinoma multicellular spheroids. Am J Pathol. 2001;159(6):2071-2080.

43. Lee JG, Ahn JH, Jin Kim T, Ho Lee J, Choi JH. Mutant p53 promotes ovarian cancer cell adhesion to mesothelial cells via integrin $\beta 4$ and Akt signals. Sci Rep. 2015;5:12642.

44. Adorno M, et al. A mutant-p53/Smad complex opposes p63 to empower TGFbeta-induced metastasis. Cell. 2009;137(1):87-98.

45. Zhu J, et al. Gain-of-function p53 mutants co-opt chromatin pathways to drive cancer growth. Nature. 2015;525(7568):206-211.

46. Muller PA, Vousden KH. p53 mutations in cancer. Nat Cell Biol. 2013;15(1):2-8.

47. Pfister NT, et al. Mutant p53 cooperates with the SWI/SNF chromatin remodeling complex to regulate VEGFR2 in breast cancer cells. Genes Dev. 2015;29(12):1298-1315.

48. Kogan-Sakin I, et al. Mutant p53(R175H) upregulates Twist1 expression and promotes epithelial-mesenchymal transition in immortalized prostate cells. Cell Death Differ. 2011;18(2):271-281.

49. Haenssen KK, et al. ErbB2 requires integrin alpha5 for anoikis resistance via Src regulation of receptor activity in human mammary epithelial cells. J Cell Sci. 2010;123(Pt 8):1373-1382.

50. Goncharova EJ, Kam Z, Geiger B. The involvement of adherens junction components in myofibrillogenesis in cultured cardiac myocytes. Development. 1992;114(1):173-183.

51. Puch S, et al. N-cadherin is developmentally regulated and functionally involved in early hematopoietic cell differentiation. $J$ Cell Sci. 2001;114(Pt 8):1567-1577.

52. Matsumura T, Wolff K, Petzelbauer P. Endothelial cell tube formation depends on cadherin 5 and CD31 interactions with filamentous actin. J Immunol. 1997;158(7):3408-3416.

53. Dharma Rao T, et al. Novel monoclonal antibodies against the proximal (carboxy-terminal) portions of MUC16. Appl Immunohistochem Mol Morphol. 2010;18(5):462-472.

54. Zhang Y, Yan W, Chen X. Mutant p53 disrupts MCF-10A cell polarity in three-dimensional culture via epithelial-to-mesenchymal transitions. J Biol Chem. 2011;286(18):16218-16228.

55. Dong $\mathrm{P}$, et al. Mutant p53 gain-of-function induces epithelial-mesenchymal transition through modulation of the miR-130bZEB1 axis. Oncogene. 2013;32(27):3286-3295.

56. Jiang FZ, et al. Mutant p53 induces EZH2 expression and promotes epithelial-mesenchymal transition by disrupting p68-Drosha complex assembly and attenuating miR-26a processing. Oncotarget. 2015;6(42):44660-44674.

57. Blanden AR, et al. Synthetic metallochaperone ZMC1 rescues mutant p53 conformation by transporting zinc into cells as an ionophore. Mol Pharmacol. 2015;87(5):825-831.

58. Yu X, et al. Small molecule restoration of wildtype structure and function of mutant p53 using a novel zinc-metallochaperone based mechanism. Oncotarget. 2014;5(19):8879-8892.

59. Yu X, Narayanan S, Vazquez A, Carpizo DR. Small molecule compounds targeting the p53 pathway: are we finally making progress? Apoptosis. 2014;19(7):1055-1068.

60. Yu X, Vazquez A, Levine AJ, Carpizo DR. Allele-specific p53 mutant reactivation. Cancer Cell. 2012;21(5):614-625

61. Nieman KM, et al. Adipocytes promote ovarian cancer metastasis and provide energy for rapid tumor growth. Nat Med. 2011;17(11):1498-1503.

62. Jarboe E, et al. Serous carcinogenesis in the fallopian tube: a descriptive classification. Int J Gynecol Pathol. 2008;27(1):1-9.

63. Karst AM, Drapkin R. Ovarian cancer pathogenesis: a model in evolution. J Oncol. 2010;2010:932371.

64. Crum CP, Drapkin R, Kindelberger D, Medeiros F, Miron A, Lee Y. Lessons from BRCA: the tubal fimbria emerges as an origin for pelvic serous cancer. Clin Med Res. 2007;5(1):35-44.

65. Shield K, Ackland ML, Ahmed N, Rice GE. Multicellular spheroids in ovarian cancer metastases: biology and pathology. Gynecol Oncol. 2009;113(1):143-148.

66. Kuhn E, et al. The diagnostic and biological implications of laminin expression in serous tubal intraepithelial carcinoma. Am $J$ Surg Pathol. 2012;36(12):1826-1834.

67. Sood AK, et al. Adrenergic modulation of focal adhesion kinase protects human ovarian cancer cells from anoikis. J Clin Invest. 2010;120(5):1515-1523.

68. Halder J, et al. Therapeutic efficacy of a novel focal adhesion kinase inhibitor TAE226 in ovarian carcinoma. Cancer Res. 2007;67(22):10976-10983.

69. Ye X, Weinberg RA. Epithelial-mesenchymal plasticity: a central regulator of cancer progression. Trends Cell Biol. 2015;25(11):675-686.

70. Yang Z, et al. Up-regulation of gastric cancer cell invasion by Twist is accompanied by N-cadherin and fibronectin expression Biochem Biophys Res Commun. 2007;358(3):925-930.

71. Cheng GZ, Chan J, Wang Q, Zhang W, Sun CD, Wang LH. Twist transcriptionally up-regulates AKT2 in breast cancer cells leading to increased migration, invasion, and resistance to paclitaxel. Cancer Res. 2007;67(5):1979-1987.

72. Yu M, et al. Circulating breast tumor cells exhibit dynamic changes in epithelial and mesenchymal composition. Science. 2013;339(6119):580-584.

73. Ting DT, et al. Single-cell RNA sequencing identifies extracellular matrix gene expression by pancreatic circulating tumor cells. Cell Rep. 2014;8(6):1905-1918.

74. Aceto N, et al. Circulating tumor cell clusters are oligoclonal precursors of breast cancer metastasis. Cell. 2014;158(5):1110-1122.

75. Zhang Y, Yan W, Chen X. P63 regulates tubular formation via epithelial-to-mesenchymal transition. Oncogene. 2014;33(12):1548-1557.

76. Tran $\mathrm{MN}$, et al. The $\mathrm{p} 63$ protein isoform $\Delta \mathrm{Np} 63 \alpha$ inhibits epithelial-mesenchymal transition in human bladder cancer cells: role of MIR-205. J Biol Chem. 2013;288(5):3275-3288. 
77. Tucci P, et al. Loss of p63 and its microRNA-205 target results in enhanced cell migration and metastasis in prostate cancer. Proc Natl Acad Sci USA. 2012;109(38):15312-15317.

78. Muller PA, et al. Mutant p53 drives invasion by promoting integrin recycling. Cell. 2009;139(7):1327-1341.

79. Liao XY, Xue WC, Shen DH, Ngan HY, Siu MK, Cheung AN. p63 expression in ovarian tumours: a marker for Brenner tumours but not transitional cell carcinomas. Histopathology. 2007;51(4):477-483.

80. Wang Y, et al. Restoring expression of wild-type p53 suppresses tumor growth but does not cause tumor regression in mice with a p53 missense mutation. J Clin Invest. 2011;121(3):893-904.

81. Soragni A, et al. A designed inhibitor of p53 aggregation rescues p53 tumor suppression in ovarian carcinomas. Cancer Cell. 2016;29(1):90-103.

82. Shin Y, et al. Microfluidic assay for simultaneous culture of multiple cell types on surfaces or within hydrogels. Nat Protoc. 2012;7(7):1247-1259. 